\title{
Influence of Non-Uniform Heat Flux Distributions on the Secondary flow, Convective Heat Transfer and Friction Factors For a Parabolic Trough Solar Collector Type Absorber Tube
}

Izuchukwu F. Okafor, Jaco Dirker* and Josua P. Meyer**

Department of Mechanical and Aeronautical Engineering, University of Pretoria, Pretoria, Private Bag X20,

Hatfield 0028, South Africa.

*Corresponding Author:

Email Address: jaco.dirker@up.ac.za

Phone: $+27(0) 124202465$

**Alternative Corresponding Author:

Email Address: josua.meyer@up.ac.za

Phone $+27(0) 124203104$

\section{Highlights}

-Thermal analysis of a parabolic trough collector (PTC) for laminar flow liquid water heating.

-Buoyancy effects are less significant in flat plate solar water heaters but significantly enhance PTC efficiency.

-With buoyancy effects, average and axial local internal heat transfer coefficients are far greater than when neglected.

-Internal heat transfer coefficients increased with heat flux intensity and absorber tube inlet fluid temperature.

-Friction factors decreased with an increase in the inlet fluid temperature. 


\begin{abstract}
Non-uniform heat flux profiles on circular tubes are found in a number of heat transfer applications, including solar heating. In this numerical study the influence of the circumferential angle spans of non-uniform heat flux distributions are considered on the secondary buoyancy-driven flow, internal fluid heat transfer coefficients, and friction factors in horizontal absorber tubes in parabolic trough solar collector applications for water heating in the laminar flow regime. Inlet Reynolds numbers ranging from 130 to 2200 for $10 \mathrm{~m}$ long tubes with different inner diameters were considered. Sinusoidal type incident heat flux distributions, tube-wall heat conduction and heat losses were taken into account. It was found that due to buoyancy-driven secondary flow, overall and local internal heat transfer coefficients were increased significantly due to the non-uniformity of the incident heat flux. Average internal heat transfer coefficient increased with the heat flux intensity, the incident heat flux angle span and the inlet fluid temperature. The effective friction factor decreased with an increase in the absorber tube inlet fluid temperature. It was found that improved thermal efficiencies can be achieved for low mass flow rate water heating applications by employing parabolic trough collector systems compared to flat plate systems.
\end{abstract}

Keywords: parabolic trough; absorber tube; heat transfer coefficients; friction factor; nonuniform heat flux distributions; secondary flow 


\section{Nomenclature}

surface or cross sectional area, $\mathrm{m}^{2}$

$C_{\text {bond }}$

metal bond thermal conductance, $\mathrm{W} / \mathrm{mK}$

$c_{p}$

specific heat of the fluid, $\mathrm{J} / \mathrm{kg} \mathrm{K}$

$D \quad$ tube diameter, $\mathrm{m}$

$e$

air-gap width, $\mathrm{m}$

$f$

Darcy friction factor

$g$

acceleration due to gravity, $\mathrm{m} / \mathrm{s}^{2}$

HCE heat collector element

HTF heat transfer fluid

$h, \bar{h} \quad$ heat transfer coefficient and average heat transfer coefficient, $\mathrm{W} / \mathrm{m}^{2} \mathrm{~K}$

I number of heated divisions

$i \quad$ heated division number

$k \quad$ thermal conductivity, $\mathrm{W} / \mathrm{m} \mathrm{K}$

$L, L_{T O T} \quad$ axial dimension and total axial length of tube, $\mathrm{m}$

$M \quad$ total number of the axial divisions

$\dot{m} \quad$ mass flow rate, $\mathrm{kg} / \mathrm{s}$

$(m, n) \quad$ numerical surface location

$N \quad$ total number of the circumferential divisions

$\mathrm{Nu}, \overline{\mathrm{Nu}} \quad$ Nusselt number and average Nusselt number

$P \quad$ pressure, $\mathrm{Pa}$

$p \quad$ centre-to-centre distance, $\mathrm{m}$

Pr Prandtl number

$q \quad$ heat transfer, $\mathrm{W}$

$q^{\prime \prime} \quad$ heat flux, $\mathrm{W} / \mathrm{m}^{2}$ 
thermal resistance, $\mathrm{K} / \mathrm{W}$

$r$

radial coordinate, $\mathrm{m}$

$\operatorname{Re}$

Reynolds number

$T, \bar{T} \quad$ temperature and average temperature, $\mathrm{K}$

$t \quad$ tube wall thickness, $\mathrm{m}$

$U$

overall heat transfer coefficient, $\mathrm{W} / \mathrm{m}^{2} \mathrm{~K}$

V

kinetic viscosity, $\mathrm{m}^{2} / \mathrm{s}$

$v, \bar{v} \quad$ velocity and average velocity, $\mathrm{m} / \mathrm{s}$

$x$

axial coordinate, $\mathrm{m}$

$W$

collector aperture, $\mathrm{m}$

\section{Greek letters}

$\alpha$

angle span of the heated segment of the tube, ${ }^{\circ}$

$\alpha_{w} \quad$ absorptivity of tube surface

$\beta \quad$ thermal expansion coefficient of the heat transfer fluid, $\mathrm{K}^{-1}$

$\varepsilon_{t u} \quad$ emissivity of the tube-wall surface

$\varepsilon_{g} \quad$ emissivity of glass surface

$\eta \quad$ thermal efficiency

$\mu \quad$ viscosity, $\mathrm{kg} / \mathrm{ms}$

$\rho \quad$ density of the heat transfer fluid, $\mathrm{kg} / \mathrm{m}^{3}$

$\sigma$

Stefan-Boltzmann constant, $\mathrm{W} / \mathrm{m}^{2} \mathrm{~K}^{4}$

$\phi$

angle span of each circumferential division, ${ }^{\circ}$, or tangential dimension

$\phi_{\text {in }} \quad$ incident angle, ${ }^{\circ}$,

$\Re \quad$ radius, $m$

$\tau_{g} \quad$ transmittivity of glass cover 


\section{Subscripts}

$a$

free stream air

atm

atmospheric

b bulk fluid property

conv convection

col collector

$D_{i} \quad$ referring to the inner diameter

f $\quad$ fluid

FP flat plate

g glass

$i \quad$ inner surface

$m \quad$ at position $m$

$n \quad$ at position $n$

$o \quad$ outer surface or reference value

PT parabolic trough

$r \quad$ in radial direction

rad radiation

$S \quad$ solar

tu tube

w wall

W $\quad$ referring to width

$x \quad$ in axial direction

$\phi \quad$ in tangential direction

$\infty \quad$ radiant surroundings 


\section{Introduction}

Parabolic trough solar collectors are suitable for a wide range of applications, which include steam production for power generation, industrial process heating, solar cooling, and institutional and domestic hot water system [1]. Besides hot water systems for domestic use, several industrial applications require hot water temperatures below $100{ }^{\circ} \mathrm{C}$ [2]. Therefore, the investigation of single phase water in solar collector tubes is an important one. The fluid flow regime could be turbulent or laminar depending on the application and operating conditions. The earlier designs and development of parabolic trough solar collector systems were focused on large-scale applications suitable for power generation [3], where the collectors are operated in the turbulent flow regime to increase the effective fluid side heat transfer coefficient which assists in improving the thermal efficiency of the collector system. However, opportunities exist to take advantage of buoyancy-driven secondary flow effects, which can greatly enhance heat transfer coefficients in the laminar or weak turbulent flow regimes. Often, the commercial, institutional and domestic solar water heating systems are developed to operate as active systems at high or low mass flow rate or as passive systems (e.g. thermosyphons) without the need of a mechanical pump [4], which inevitably reduces the fluid mass flow rate.

Of particular interest in this paper is a parabolic trough type solar collector system application where space restriction could exist. Shown in Fig 1 a, is a proposed lay-out for such a system which consists of a single fluid tube heated from below via concentrated solar rays reflected by a parabolic surface. This arrangement could be a viable alternative to traditional flat-plate collectors which usually are connected in arrays for generating hot water. Flat plat collectors have many advantages, such as simplicity of design, but they also have weaknesses. They are seldom equipped with sun-tracking systems due to the excessive weight of the heat transfer 
fluid in the collector tubes, making it difficult to alter the orientation of the plate collector. Because they usually suffer from high thermal losses due to their larger absorber surface areas required for intercepting the solar radiation, they exhibit poorer thermal performances compared to other solar collector types, such as evacuated tube collectors, compound parabolic collectors, linear Fresnel collectors, parabolic trough collectors and cylindrical trough collectors [5]. By contrast, the adaption of a parabolic trough solar collector system intercepts and concentrates the solar radiations on a smaller absorber surface area. The smaller surface area can offset the increase heat loss rate due to higher elevated surface temperatures that are obtained (due to the concentrated nature of the incident heat flux) and hence lower thermal losses and result in higher thermal efficiency.

\section{Parabolic trough collector}

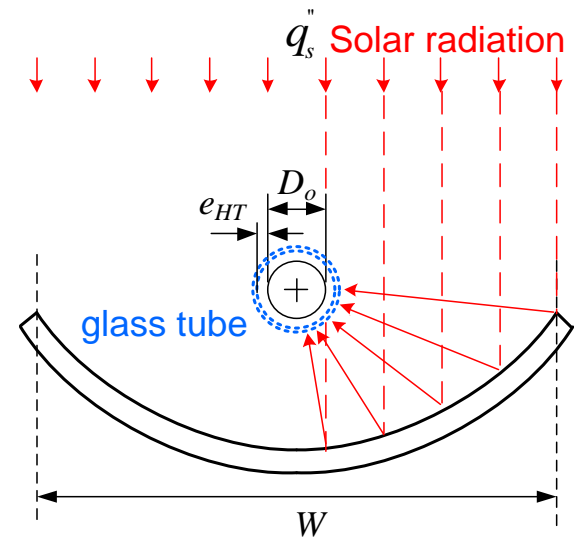

(a)

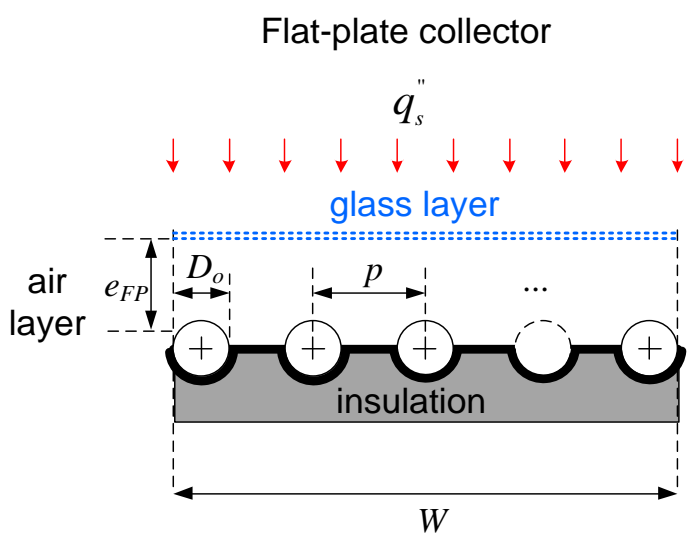

(b)

Fig.1 (a) Parabolic trough solar collector lay-out and (b) Flat plate collector lay-out.

In parabolic trough solar collectors, non-uniform heat flux distributions around the tubecircumference is present due to the reflected concentrated solar rays impinging the absorber tube surface from below [6]. For laminar flow regime cases, this will result in a significant buoyancy induced secondary flow component within the tube [7], which will increase the thermal mixing rate of the fluid. Hereby the fluid that is heated at the lower edge of the tube is forced upward and replaced by colder fluid drawn down by gravity. Therefore, increased 
internal heat transfer coefficients and friction factor characteristics are obtained. The increased internal heat transfer coefficient could improve the thermal efficiency of the collector system. Unlike with the case of a traditional flat-plate collector, the induced secondary flow effects are very much reduced due to heating occurring from the top surface of the tubes and where the gravitational force component is not able to induce significantly strong secondary flow circulation in the fluid.

The impact of buoyancy driven flow and the effect of partial uniform heating have been addressed to some extent in literature. Even though He et al. [6] considered non-uniform heat flux boundaries for a parabolic trough collector, they only considered turbulent flow regimes where buoyancy induced flow is not significant enough to take into consideration. In a numerical example by Patankar [8], where fully developed laminar flow is considered in a heated horizontal tube subjected to partial uniform heating on the top and bottom half portions respectively, it is shown that more pronounced buoyancy effects are present for the bottom-heating case which results in higher heat transfer enhancement than for the top heating case. Zeitoun [9] numerically investigated the heat transfer for laminar flow in partial uniformly heated horizontal tubes, but without considering buoyancy effect. Other numerical studies by Boufendi and Afrid [10], Touahri and Boufendi, [11] and Piva et al. [12] and experimental studies by Ghajar and Tam [13], Mohammed and Salman [14], Coutier and Greif [15], Bergles and Simonds [16] for the laminar flow only considered uniform heating of a horizontal tube, indicated that both the Nusselt numbers and friction factors are much higher than those obtained by neglecting buoyancy-induced secondary flow. Forristall [17] carried out a heat transfer analysis and modelling of a parabolic trough solar receiver. He assumed uniform heat fluxes, thermodynamic properties and temperatures around the circumference of the tube for laminar and turbulent flow conditions. However, buoyancy- 
driven secondary flow was not investigated. A parametric study by Manikandan et al. [18] on a parabolic trough solar collector system was also based on uniform heat flux, while buoyancy-driven secondary flow was not considered.

The influence of buoyancy-driven secondary flow on the forced-convective heat transfer processes due to circumferential non-uniform heating of an absorber tube in a laminar or weak turbulent flow regime still remains unexplored. Little to no information could be found that would be useful to thermal design engineers that could indicate the effect of buoyancy induced flow for cases where heat flux is non-uniform at low mass flow rates. Further to this, fully developed flow at the inlet of a heat transfer tube is seldom present in real world applications. The limited amount of information could be due to the complexity of such thermal boundary conditions and the difficulties in achieving the non-uniform thermal boundary conditions in an experimental set-up and also the interaction needed between raytracing and the numerical modelling of the heat transfer fluid [6]. When considering the buoyancy-driven secondary flow phenomenon, the classical heat transfer correlations found for uniform heating condition could be inappropriate for non-uniform heating boundary condition.

Due to the lack of information, as highlighted above, our aim in this study is to numerically determine the influence of the circumferential spans of a non-uniform heat flux distributions on the internal convective heat transfer and friction factor characteristics for an absorber tube. This work therefore gives an indication on whether an adapted parabolic trough solar collector system could be a viable heating approach for users of high volumes of hot water, and indeed so, what the anticipated heat transfer coefficients could be. 
In Section 2 of the paper, the thermal principles at work in an adapted linear trough collector is considered, which can be used to identify the operating condition which will favour the selection of such a system above a flat-plate system, with specific focus on the internal heat transfer coefficient. Sections 3 and beyond of the paper is dedicated to determining the effective heat transfer coefficients and friction factors numerically.

\section{First order thermal performance models}

\subsection{Physical model description and modelling assumptions}

As mentioned, Fig. 1(a) shows a representation of a parabolic trough solar collector lay-out with a reflector field which concentrates the solar radiation onto the bottom portion of the tube. The absorber tube has an outer diameter of $D_{o}$, an inner diameter of $D_{i}$ and a length of L. For comparison purposes, Fig. 1(b) shows a traditional flat-plate collector lay-out type which consists of a number of parallel tubes bonded onto a metal plate, each with an outer diameter of $D_{o}$, an inner diameter of $D_{i}$, and a length of $L$, spaced at a centre-to-centre distance of $p$. Thermal insulation is present at the bottom of the metal plate. Solar radiation hits the upper part of the tubes with additional heat being conducted via the collector plate to bonded joints. Both collectors are exposed to the same amount of incident heat flux intensity,

$q_{s}^{\prime \prime}$ from the sun as could be the case when the sun is at its zenith position. Both collectors can be additionally insulated by the inclusion of a glass cover at a distance of $e$ from the metal plate for the flat plate collector and a glass cover at a distance $e$ from the outer diameter of the collector tube for the parabolic trough collector.

Our intent is to perform a first order comparison of the efficiency of the two collectors under laminar flow conditions in order to determine the proportion of the intercepted solar radiation absorbed into the heat transfer fluid. In order to simplify the calculations, the following 
assumptions were made: (i) Thermal properties of the heat transfer fluid (liquid water) and the collector materials are assumed constant and independent of temperature except for the fluid density and viscosity of the fluid varied for the inlet temperature range of $290 \mathrm{~K}$ to $340 \mathrm{~K}$ considered in the present study (as is discussed in Section 3 and beyond of this paper). (ii) The energy absorbed and the reflection loss for the glass cover were neglected and the incident angle of $0^{\circ}$ was considered. The anti-reflectance of the glass was assumed of having no effects on the relative comparison of the thermal efficiency. (iii) The thermal resistance in the metal components are neglected compared to the thermal resistance of the other components. (iv) Heat losses through insulation of the collectors and from the edges and supports of the collector were neglected. (v) The heat flux losses via convection and radiation were modelled based on the first-order approximations. (vi) The fluid flow through systems is assumed incompressible and the systems operate under steady state conditions.

As shown in Figs 1 (a) and (b), the effective collector area for both the parabolic trough and traditional flat-plate collector lay-outs intercepting the incident solar radiation is:

$$
A_{c o l}=L W
$$

The heat received by the parabolic trough collector tube surface is presented in Eq. (2).

$$
q_{c o l, P T}=\alpha_{w} \eta \tau_{g} q_{s}^{\prime \prime} A_{c o l}=\alpha_{w} \eta \tau_{g} q_{s}^{\prime \prime} L W
$$

Here the reflector efficiency is $\eta$, the absorptivity of the tube surface is $\alpha_{w}$ and the transmittance of the glass cover is $\tau_{g}$. 
For the heat received by the absorber plate for the flat-plate collector lay-out is given (without reflector efficiency) as:

$$
q_{c o l, F P}=\alpha_{w} \tau_{g} q_{s}^{\prime \prime} A_{c o l}=\alpha_{w} \tau_{g} q_{s}^{\prime \prime} L W
$$

In order to determine the heat transfer rate absorbed into the heat transfer fluid, the energy balance principle is utilized. Refer to Fig. 2 showing a first order thermal resistance network linking the metal collector tube surface at temperature $T_{w}$, with the fluid within at temperature $T_{b}$, and the ambient at a temperature $T_{\infty}$. The heat received, $q_{c o l}$, is incident only on the outer surface of the metal collector since heat absorption in the glass and air layers are ignored, since it would have the same impact on both the collector types. For the flat-plate collector the entire absorption plate is approximated to be at a temperature of $T_{w}$. In reality a temperature difference will be present which reduces the efficiency of such a collector system. This conservative approach does not alter the outcome of this comparison as will be shown later.

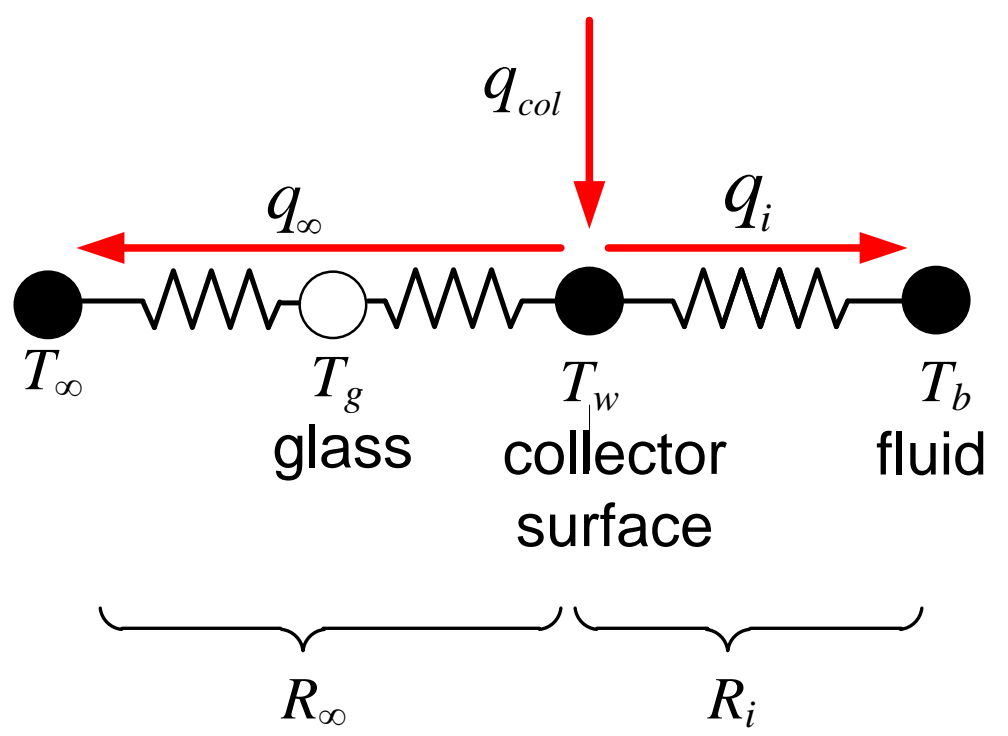

Fig. 2 First order thermal resistance network. 
For steady state conditions the heat flow to the fluid, $\dot{q}_{i}$, and to the ambient, $\dot{q}_{\infty}$, can be expressed as:

$$
q_{c o l}=q_{i}+q_{\infty}=\frac{\left(T_{w}-T_{b}\right)}{R_{i}}+\frac{\left(T_{w}-T_{\infty}\right)}{R_{\infty}}
$$

Here $R_{i}$ and $R_{o}$ are the effective overall average thermal resistance to the heat transfer fluid and the thermal resistance to the ambient via the glass layer (if present).

The thermal resistance to the fluid for the flat-plate collector is given by employing the average inner tube heat transfer coefficient, $\bar{h}_{i}$, the total inner heat transfer surface, $\pi D_{i} L W / p$, the thermal conductance over the metal bond between the collector plate the tube wall, $C_{b o n d}$, and the total length of the bonds for all the tubes, $L W / p$ :

$$
R_{i, F P}=\frac{p}{\pi D_{i} L W \bar{h}_{i}}+\frac{p}{C_{\text {bond }} L W}
$$

The thermal conduction in the tube wall is ignored for now due to the low significance that it has on the performance of the collector system in this comparison. It is, however, included in later sections of this paper when more detailed analyses are conducted. The value of $C_{b o n d}$ based on experiments of commercial solar collectors has been reported to range from 2 $\mathrm{W} / \mathrm{mK}$ to $6 \mathrm{~W} / \mathrm{mK}[20]$. A value of $4 \mathrm{~W} / \mathrm{mK}$ is adopted here.

For the parabolic trough solar collector, which only has one collector absorber tube, the thermal resistance to the fluid is given as: 


$$
R_{i, P T}=\frac{1}{\pi D_{i} L \bar{h}_{i}}
$$

For the thermal resistance to the ambient, the following are taken into consideration: the air gap thermal conduction resistance acting as an insulation layer, first order radiation heat transfer between the glass and the collector surface over the air gap, external convection heat transfer from the glass surfaces, and radiation heat emitted from the glass surface.

For the flat-plate collector the thermal resistance to the ambient is given as, based on the full collector surface area, $L W$ :

$$
R_{\infty, F P}=\frac{1}{L W}\left[\left(\frac{k_{a}}{e_{F P}}+\frac{\sigma\left(T_{w}^{4}-T_{g}^{4}\right)}{\left(1 / \varepsilon_{t u}+1 / \varepsilon_{g}-1\right)\left(T_{w}-T_{g}\right)}\right)^{-1}+\left(\bar{h}_{o}+\frac{\sigma \varepsilon_{g}\left(T_{g}^{4}-T_{\infty}^{4}\right)}{T_{g}-T_{\infty}}\right)^{-1}\right]
$$

Here $k_{a}$ is the thermal conductivity of the air-gap having a width of $e_{F P}$ and was evaluated at the average steady state temperature between $T_{w}$ and $T_{g}$. The radiative heat balance between the collector plate and the glass was evaluated as that of two infinite parallel plates given by $q=\sigma L W\left(T_{w}^{4}-T_{g}^{4}\right) /\left(1 / \varepsilon_{t u}+1 / \varepsilon_{g}-1\right)$. Here $\varepsilon_{t u}$ and $\varepsilon_{g}$ are the emissivities from the collector and glass surfaces with $\varepsilon_{t u}=0.0003 T_{w}+0.3171$ [21] and $\varepsilon_{g}=0.91$ is the emissivity of the glass cover of the collector considered, which represents that of Pyrex glass [22] also used in the Schott's heat collector element (HCE) [23]. The external convection heat transfer coefficient, $\bar{h}_{0}$, is based on the following Nusselt number relationship for flow over a flat plate in terms of the Reynolds number and Prandtl number: $\overline{\mathrm{Nu}}_{W}=0.664 \operatorname{Re}_{W}^{\frac{1}{2}} \operatorname{Pr}^{\frac{1}{3}}$ with an air-speed of $15 \mathrm{~km} / \mathrm{hr}$ (arbitrary value) and all air properties evaluated at $300 \mathrm{~K}$. The radiation heat loss is expressed as $q=\sigma \varepsilon_{g} L W\left(T_{g}^{4}-T_{\infty}^{4}\right)$. For simplicity, convection and radiation 
temperature sink values are taken to be the same at $T_{\infty}$. In reality different heat sink temperatures should be used, but this will only complicate the comparison and will not alter the key outcomes.

Similarly, for the parabolic trough collector, the thermal resistance to the ambient is given as:

$$
R_{\infty, P T}=\frac{1}{\pi\left(D_{o}+2 e_{P T}\right) L}\left[\left(\frac{k_{a}}{e_{P T}}+\frac{\sigma\left(T_{w}^{4}-T_{g}^{4}\right)}{\left(1 / \varepsilon_{t u}+1 / \varepsilon_{g}-1\right)\left(T_{w}-T_{g}\right)}\right)^{-1}+\left(\bar{h}_{0}+\frac{\sigma \varepsilon_{g}\left(T_{g}^{4}-T_{\infty}^{4}\right)}{T_{g}-T_{\infty}}\right)^{-1}\right]
$$

Here, for simplicity the thermal resistance relationship over the cylindrical gap is approximated as linear (valid if the air gap is relatively small), and applied over the outer surface of the glass tube, $\pi\left(D_{o}+2 e_{P T}\right) L$, by ignoring the thickness of the glass itself. The convection heat transfer coefficient on the outer surface, $\bar{h}_{o}$, is expressed as $\bar{h}_{o}=5.7+3.8 v$ [5] and is related to the same air speed, $v$, used for the flat plate collector. The radiation heat loss is dealt with in the same manner as in the flat plat collector, but only applied to the outer surface of the single glass tube and the radiation exchange with the solar concentrator was omitted. If these were to be included, the calculated performance of the collector will increase. As will be shown, this conservative approach does not alter the key outcomes of this comparison.

The thermal performance (or efficiency) of each collector type is expressed as the proportion of the intercepted solar radiation over the entire collector surface, that is taken up by the heat transfer fluid, $q_{i}$ : 


$$
\eta_{c o l}=\frac{q_{i}}{q_{s}^{\prime \prime} L W}
$$

\subsection{Indicative thermal performance comparison}

Besides the input values already mentioned earlier, the following values were used as inputs for the initial comparison: $D_{o}=40 \mathrm{~mm}, D_{i}=35 \mathrm{~mm}, p=80 \mathrm{~mm}, W=1 \mathrm{~m}, L=2 \mathrm{~m}$, $e_{F P}=e_{P T}=25 \mathrm{~mm}, \eta=0.9, T_{a t m}=T_{\infty}=27^{\circ} \mathrm{C}$ and $\alpha_{w}=0.85$ is the absorptivity of the absorber tube, which represents an absorber tube with iron oxide coating [24]. These inputs were used for demonstration purposes. The resulting overall collector efficiencies are determined in terms of the difference between the local bulk fluid temperature and the ambient temperature for $q_{s}^{\prime \prime}=1000 \mathrm{~W} / \mathrm{m}^{2}$. This heat flux value was chosen to represent a clear sunny day. It should be noted that the radiation heat flux used for the traditional flat-plate collector is global radiation and the same radiation heat flux value is used for the parabolic trough solar collector and was considered as beam radiation. Also, different inner tube wall heat transfer coefficients, based on the Nusselt number are considered. As reference datum, a Nusselt number of 4.36 for both the flat plate and parabolic trough collectors are used, as this is generally associated with fully developed flow under uniform wall heat flux conditions (without secondary flow effects). For developing flow, close to the inlet to the collector tube, higher Nusselt number can be expected. However, for demonstration purposes the more conservative fully developed flow Nusselt number is used in the datum case. In the parabolic trough collector, however, since concentrated heating occurs from below and there is a circumferential non-uniform heat flux distribution, a significant amount of buoyancy driven secondary flow is present within the tube which results in a higher enhancement of the internal convective heat transfer. For that reason Nusselt numbers of 10 and 15 for the parabolic trough collector are also considered. The extent of the increased internal heat transfer coefficients are dealt with in Section 4 of this paper. The higher Nusselt numbers are 
not considered for the flat plate collector because of the uniform heating which occurs from the top surface of the absorber tubes and thus, little to no heat transfer enhancement will be present, as mentioned earlier.

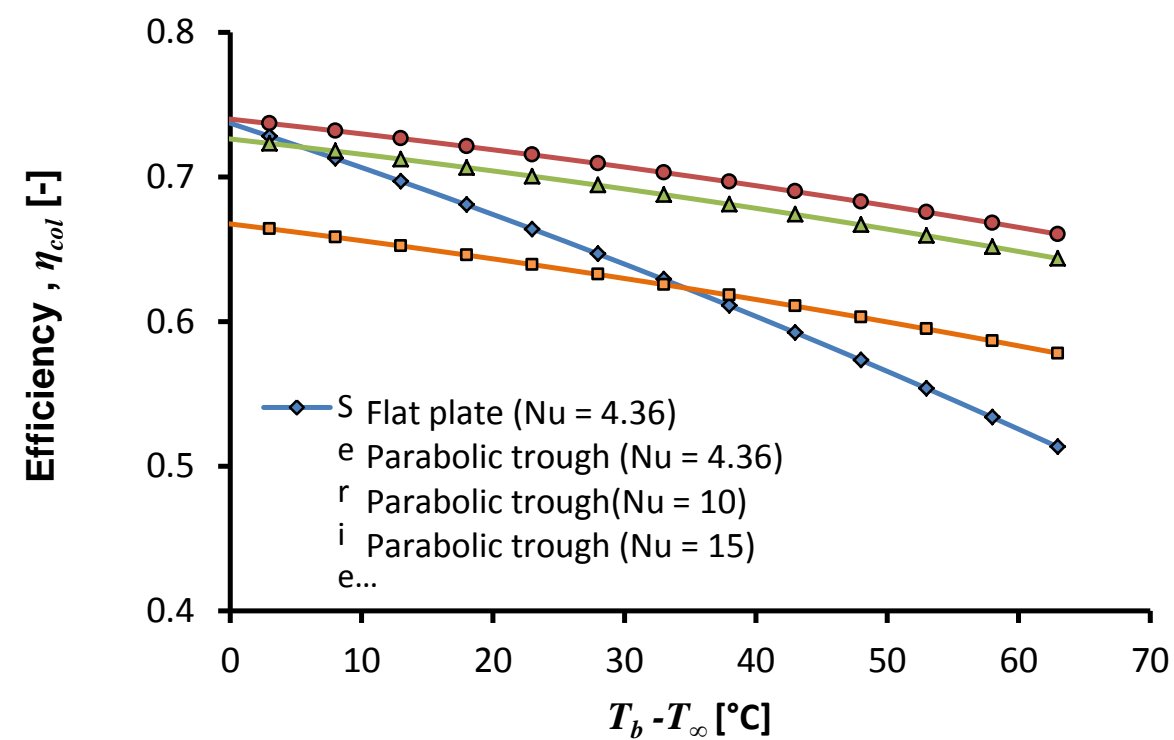

Fig. 3 Overall efficiency of both collector lay-outs for $\mathrm{Nu}=4.36$, as well as for $\mathrm{Nu}=10$ and $\mathrm{Nu}=15$ for the parabolic trough collector for $q_{s}^{\prime \prime}=1000 \mathrm{~W} / \mathrm{m}^{2}$.

Fig 3 indicates the steady state overall efficiency for two collector types in terms of the difference in temperature between the average internal bulk water temperature and the surrounding temperature for $q_{s}^{\prime \prime}=1000 \mathrm{~W} / \mathrm{m}^{2}$. As expected, as the fluid temperatures increase (resulting in higher temperature differences), the thermal efficiencies of the collectors decrease. From the figure, it can be seen that for the parabolic trough collector, an indicative maximum efficiency of up to $74 \%$ is obtained when an inner Nusselt number of 15 is considered. As the Nusselt number decreases, so does the collector efficiency decrease. For the flat-plate collector a highest efficiency of approximately $74 \%$ is also achieved at low fluid temperature differences. The rate of decrease in the efficiency in terms of the temperature difference is, however, the highest with the flat plate collector. For the current set of inputs, the parabolic trough collector case has a higher efficiency than the flat-plate 
collector for temperature differences above approximately $35^{\circ} \mathrm{C}$. Also, at high temperature differences the parabolic trough collector type significantly outperform the flat-plate collector in both efficiency and heat input rate (not shown).

It should be noted that the conservative assumptions made earlier, will either reduce the flat plate collector efficiency compared to the parabolic trough collector type, or influence both of the collectors efficiencies in a similar manner. Based on this first order comparison it is seen that even though the heat transfer fluid flow is laminar, a relatively small increase in the convection heat transfer coefficient can result in a significant thermal advantage when a solar concentrating system, such as a parabolic trough collector set-up is employed. Based on the indicative trend in Figs 3, it appears as though the parabolic trough collector system might be a viable option for flat plate collector system for water heating, if adapted and if a Nusselt number of 10 and more are achieved. The increased thermal performance could therefore be an acceptable trade-off for the increased complexity of this solar collector system (in terms of possible sun-follower systems) when compared to a flat-plate collector. This could be applicable to high volume hot water users.

In the sections that follow a detailed numerical investigation is conducted to better estimate the internal convective heat transfer enhancement due to the buoyancy-induced secondary flow phenomenon for different circumferential spans of a non-uniform concentrated heat flux distributions. For the remainder of the paper, no outer glass covering is considered except for the model validation purposes, in order to place focus mainly on the influence of the circumferential angle span of the impinging heat flux. The inclusion of glass cover might impact the heat flux distribution on the collector tube wall due to optical refraction, reflection and absorption. In addition, if the void between the glass cover and the tube is not evacuated, 
the thermal mass of air in the annular space could result in heat fluxes on the tube surface that are more uniform. These influences fall beyond the scope of this paper.

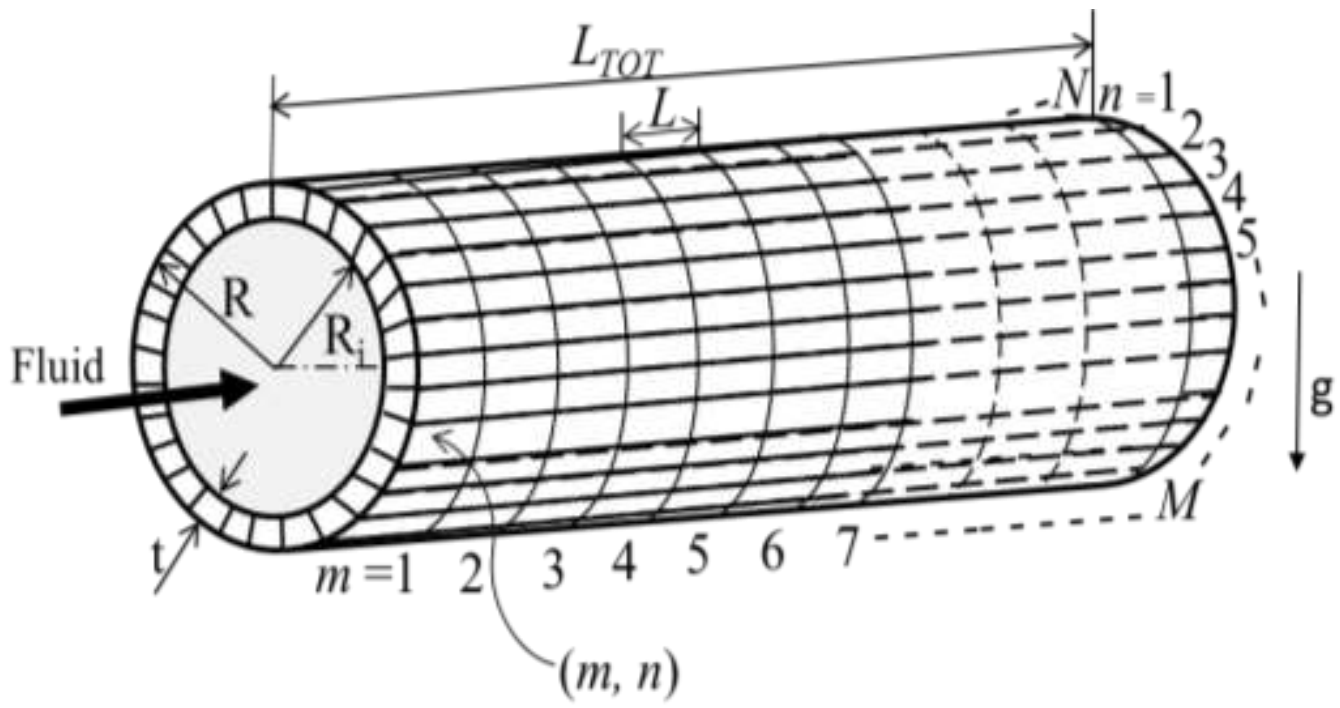

Fig.4 (a) Absorber tube model divided into $M \times N$ control surfaces and (b) circumferential non-uniform heat flux distribution over the tube model.

\section{Numerical investigation}

\subsection{Tube model}

Fig. 4 gives a more detailed representation of the geometry of an absorber tube in a horizontal orientation. For methodology description purposes the tube wall is divided into $M \times N$ number of sections (in the axial and circumferential directions respectively). The tube has a wall thickness of $t$, inner diameter $D_{i}$, outer diameter of $D_{o}$, and a total length of $L_{T O T}=10 \mathrm{~m}$, suitable for the water heating. Unless indicated otherwise, an inner diameter of $62.7 \mathrm{~mm}$, a wall thickness of $5.16 \mathrm{~mm}$, and ambient and surrounding temperature of $T_{\text {atm }}=T_{\infty}=303 \mathrm{~K}$ are considered for the remainder of this paper. This diameter and the other diameters used later in this paper were selected according to available commercial sizes. The absorber tube length was based on the LS-2 collector module which normally has absorber tube lengths of $4 \mathrm{~m}$ or more [23]. A $10 \mathrm{~m}$ length was considered for the present study, which represents the absorber tube length for two LS-2 collector modules, which could be suitable for direct water 
heating. This inner diameter results in a length-to-diameter ratio $\left(L_{T O T} / D_{i}\right)$ of 160 at the exit, but based on the numerical results, heat transfer coefficients at smaller length-to-diameter ratios can also be deduced. The tube wall has a thermal conductivity of $k_{w}=16.27 \mathrm{~W} / \mathrm{m} \mathrm{K}$, which represents stainless steel which is a suitable material for water heating applications. In this detailed analysis the conduction within the tube wall is included since radial, axial and tangential heat conduction influences the temperature and heat flux distributions on the inner surface of the tube.

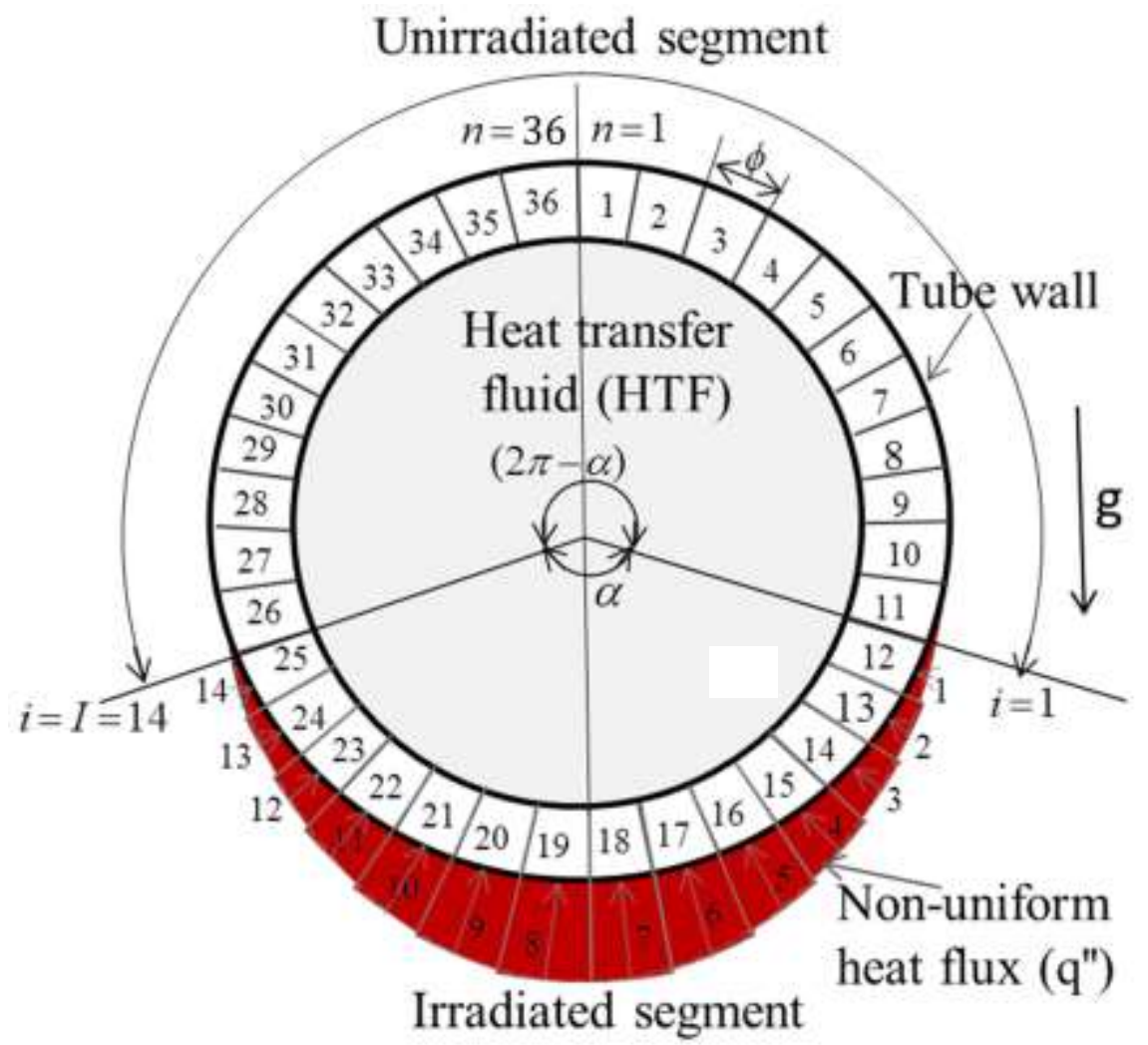

Figs 5 Cross-section of the absorber tube model with non-uniform heat flux distributions boundary.

Fig. 5 shows a circumferential non-uniform heat flux distributions over the outer-wall surface of the tube model for an effective incident heat flux angle span of $\alpha=140^{\circ}$. This angle span is a function of the reflector system width $(W)$, rim angle and the focal position of the parabolic trough. The gravitational field direction $(g)$ and the numbering system employed in simulating different circumferential heat flux distributions on the tube model are also shown. 
In this study, $N=36$ is used to piecewise uniformly describe the circumferential heat flux distributions. Each segment subtended an angle span of $\phi$ defined as:

$$
\phi=\frac{2 \pi}{N}
$$

The angle span of the heated (incident) and unirradiated portions of the absorber tube model

are $\alpha$ and $2 \pi-\alpha$ respectively. Also $n_{i=1}$ is the segment (in a clockwise fashion) where the heat flux distribution starts and can be expressed in terms of $\alpha$ in Eq. (11).

$$
n_{i=1}=\frac{[N-I]}{2}+1
$$

where $n=1,2,3 \ldots N=36$, and $i=1,2,3 \ldots I . I$ is the number of segments of the tube model that are directly heated with the external heat flux (with $\alpha$ being multiples of $20^{\circ}$ for this study), expressed in Eq. (12).

$$
I=\frac{\alpha}{2 \pi} N
$$

The non-uniform heat flux distribution boundary on the tube model is such that the lower central portion of the tube receives the maximum heat flux, which decreases upward on both sides of the tube to the top portion. For demonstration purposes, a sinusoidal function is used to model the circumferential non-uniform heat flux distribution around the absorber tube. The choice of using a sinusoidal distribution is loosely based on the ray-tracing results by Wirz et al. [25] which indicated higher heat flux intensity distributions on the lower portion and very low in the upper portion of the collector absorber tube. In a ray-tracing investigation 
conducted by $\mathrm{He}$ et al. [6] it was shown that the heat flux distribution is dependent on a number of parameters including the reflector rim angle and that in some cases there is a shadow effect due to the presence of the collector tube itself while in other cases there is no shadow effect. Those cases without the shadow effect are represented here by a sinusoidal distribution. Specific heat flux distributions can be obtained from direct ray-tracing of heat flux distribution, but are not incorporated into this study and could be investigated separately.

A discussion of the generic control volume is needed to assist with the interpretation of the inner and outer wall thermal conditions as well as the results that are given later in this paper. Fig. 6 shows a generic control volume of an element at location $(m, n)$ on the absorber tube model in Fig. 5 indicating the heat transfer components and dimensions: $L, t$ and $\phi$, in the $(x, r, \phi)$ co-ordinate system. $A_{o}$ and $A_{i}$ are the external wall surface and the wetted internal wall surface areas of the element.

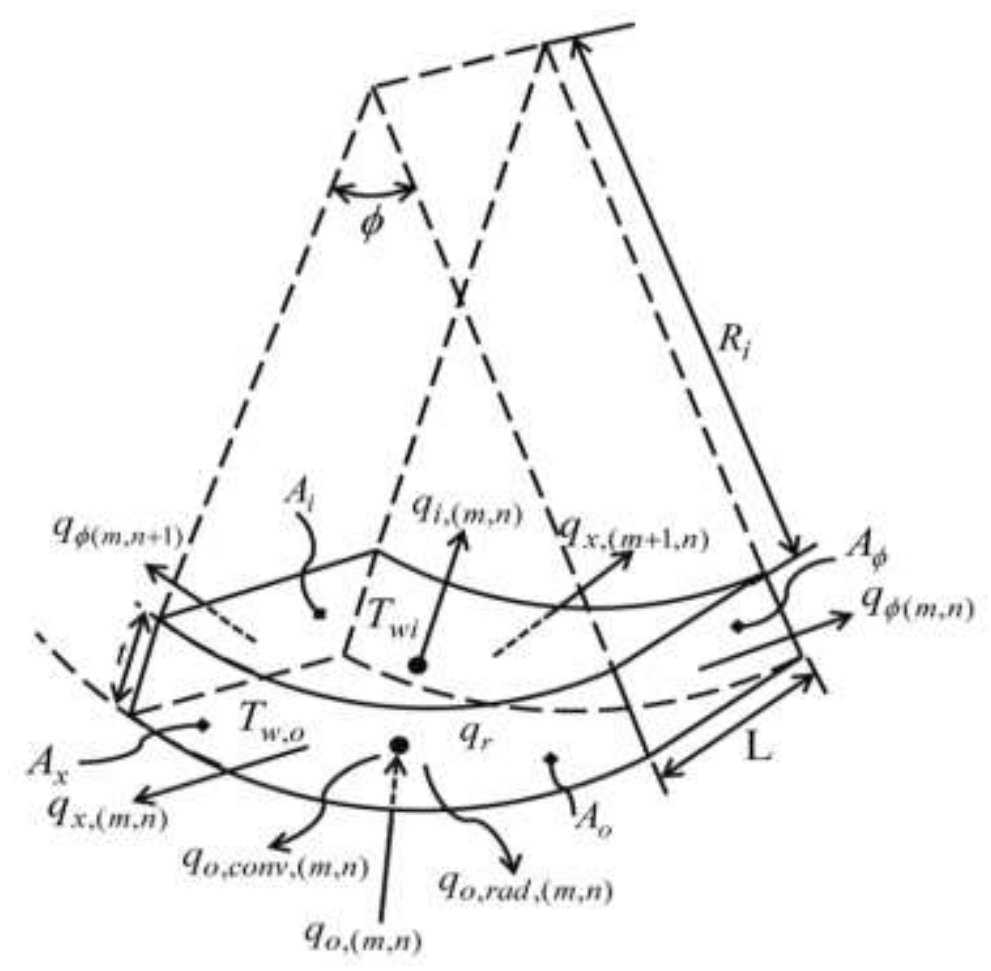

Fig. 6 Control volume of the element. 
By applying the energy balance principle to the element in Fig.7, the following can be obtained for steady-state conditions:

$$
q_{o,(m, n)}=q_{i,(m, n)}+q_{x,(m, n)}+q_{x,(m+1, n)}+q_{\phi,(m, n)}+q_{\phi,(m, n+1)}+q_{o, c o n v,(m, n)}+q_{o, \operatorname{rad},(m, n)}
$$

A brief description of each term (measured in Watts) from left to right are given in the paragraphs that follow.

$q_{o,(m, n)}$ is the incident heat transfer rate on the outer wall surface at location $(m, n)$ expressed in Eq. (14) as follows:

$$
q_{o,(m, n)}=q_{o,(m, n)}^{\prime \prime} A_{o,(m, n)}
$$

While $q_{i,(m, n)}$ is the heat transfer rate to the working fluid at location $(m, n)$ which can be expressed as follows:

$$
q_{i,(m, n)}=h_{i,(m, n)} \cdot A_{i,(m, n)}\left(T_{w, i,(m, n)}-T_{b, m}\right)
$$

where $h_{i(m, n)}$ is the hypothetical local internal heat transfer coefficient, $A_{i,(m, n)}$ is the inner wall surface area, $T_{w i,(m, n)}$ is the inner wall temperature and $T_{b, m}$ is the fluid bulk temperature at the axial position $m$ defined as:

$$
T_{b, m}=T_{b, m-1}+\frac{\sum_{n=1}^{N} q_{i,(m, n)}}{\dot{m} c_{P}}
$$


where $\dot{m}$ is the mass flow rate of the heat transfer fluid, $c_{P}$ is the specific heat of the heat transfer fluid and $T_{b, m-1}$ is the upstream local bulk fluid temperature. The average internal heat transfer coefficient $\bar{h}_{i, m}$ is related to the average Nusselt number as follows:

$$
\overline{N u}_{i, m}=\frac{\bar{h}_{i, m} D_{i}}{k_{f}}
$$

where $\bar{h}_{i, m}$ is the circumferential average internal heat transfer coefficient at location $m$ :

$$
\bar{h}_{i, m}=\frac{\sum_{n=1}^{N} q_{i,(m, n)}}{\pi D_{i} L\left(\bar{T}_{w, i, m}-T_{b, m}\right)}
$$

and where $\bar{T}_{w, i, m}$ is the circumferential average local inner-wall temperature at location $m$ :

$$
\bar{T}_{w, i, m}=\frac{1}{N} \sum_{n=1}^{N} T_{w, i,(m, n)}
$$

The average internal heat transfer coefficient, $\bar{h}_{i}$ over the full length of the tube model in terms of the overall inner-wall surface temperature, $\bar{T}_{w, i}$ can be expressed as follows:

$$
\bar{h}_{i}=\frac{\sum_{m=1}^{M} \sum_{n=1}^{N} q_{i,(m, n)}}{\pi D_{i} L_{T O T}\left(\bar{T}_{w, i}-\bar{T}_{b}\right)}
$$

Returning to Eq. (13), $q_{x,(m, n)}$ and $q_{x,(m+1, n)}$ are the conductive heat transfers in the axial direction, modelled from Fourier's law of heat conduction [26]. Also, in Eq. (13) the conductive heat transfers in the tangential direction, $q_{\phi,(m, n)}$ and $q_{\phi,(m, n+1)}$ are also modelled with the Fourier law. $q_{o, \text { conv, }(m, n)}$ is the forced-convective heat transfer loss from the outer- 
wall surface at $(m, n)$ to the surrounding of the tube modeled from Newton's law of cooling [26] as:

$$
q_{o, c o n v,(m, n)}=h_{o,(m, n)} A_{o}\left(T_{w, o,(m, n)}-T_{a t m}\right)
$$

where $T_{w, o,(m, n)}$ is the outer-wall temperature at $(m, n), T_{a t m}$ is the ambient free-stream air temperature and $h_{o(m, n)}$ is the external convective heat transfer coefficient.

The last term in Eq. (13), $q_{o, r a d,(m, n)}$, represents the first order radiative heat transfer loss to the surrounding modelled from the Stefan-Boltzmann law of the emissive power of a surface at a thermodynamic temperature as follows:

$$
q_{o, r a d,(m, n)}=\varepsilon_{t u} \sigma A_{o}\left(T_{w, o,(m, n)}^{4}-T_{\infty}^{4}\right)
$$

where $\varepsilon_{t u}$ is emissivity of the tube model expressed in using the relation mentioned earlier in terms of the tube outer-wall temperature [21] and $\sigma$ is the Stefan-Boltzmann constant being $5.67 \times 10^{-8} \mathrm{~W} / \mathrm{m}^{2} \mathrm{~K}^{4}[19]$. The average overall heat transfer coefficient, $U$ from the surrounding of the tube model to the heat transfer fluid in the tube can be expressed as [4]:

$$
U=\left[\frac{1}{U_{o}}+\frac{R_{o}}{\bar{h}_{f} R_{i}}+\frac{R_{o}}{k_{w}} \ln \left(\frac{R_{o}}{R_{i}}\right)\right]^{-1}
$$

where $U_{o}$ is the heat loss coefficient due to convective and radiative heat flux losses of the tube. When $T_{a t m}=T_{\infty}$ (as assumed in this paper for simplicity reasons), this can be written as: 


$$
U_{o}=\bar{h}_{r a d}+\bar{h}_{o}
$$

where $\bar{h}_{o}$ is the forced-convective heat transfer coefficient and $\bar{h}_{\text {rad }}$ is the average equivalent radiation heat transfer coefficient from the outer-wall surface of the tube to the surrounding expressed as:

$$
\bar{h}_{r a d}=\varepsilon_{t u} \sigma\left(\bar{T}_{w, o}+T_{\infty}\right)\left(\bar{T}_{w, o}^{2}+T_{\infty}^{2}\right)
$$

where $\bar{T}_{w, o}$ is the average outer-wall temperature of the tube model.

As mentioned, the fluid flow through the tube is assumed incompressible. The pressure drop $(\Delta p)$ along the tube length due to friction loss at the internal wall boundary can be expressed [19] as:

$$
\Delta P=f \frac{L_{T O T}}{D_{i}} \frac{\rho \bar{v}^{2}}{2}
$$

where $\bar{v}$ is the mean fluid velocity and $f$ is the friction factor.

The values for $\bar{h}_{i, m}, \bar{h}_{i}$ and $\bar{T}_{w o}$ in eqns. (18), (20) and (25) along with the friction factor in Eq. (27) were determined from the results of numerical simulations implemented in ANSYS Fluent version 14.0 [27] for different circumferential spans of uniform and sinusoidal nonuniform heat flux distribution boundary conditions. 


\subsection{Governing equations}

The governing equations of the fluid flow and heat transfer in the tube model are the continuity, momentum and energy equations and are presented in vector form [28] as follows:

$$
\begin{array}{ll}
\text { Continuity: } & \nabla \cdot(\rho \vec{v})=0 \\
\text { Momentum: } & \rho(\vec{v} \cdot \nabla) \vec{v}=-\nabla p+\mu \nabla^{2} \vec{v}+\vec{g} \rho \beta \Delta T \\
\text { Energy: } & \vec{v} \cdot\left(\vec{v}\left(\rho c_{p} T\right)\right)=\nabla \cdot(k \nabla T) \\
\text { where } & \nabla \equiv \frac{1}{r} \frac{\partial}{\partial r}+\frac{1}{r} \frac{\partial}{\partial \phi}+\frac{\partial}{\partial x} \text { and } \vec{v}=v_{r}+v_{\phi}+v_{x}
\end{array}
$$

$\beta$ is the thermal expansion coefficient of the heat transfer fluid while $v_{r}, v_{\phi}$ and $v_{x}$ are the radial, polar and axial velocity components respectively. The density term in the computational domain was assumed constant except in the body force term of the momentum equation in Eq. (28). The Boussinesq approximation [27] was employed to account for the density variation as a function of temperature (presented in section 3.4) and the effect of viscous dissipation was neglected.

\subsection{Boundary conditions}

The following boundary conditions were applied:

(i) Inlet boundary conditions $(x=0)$ :

Uniform inlet velocity was used (uniform mass flux because the fluid is incompressible), since in practice the flows in pipes rarely have fully developed velocity distributions at the inlet. Unless stated otherwise: 


$$
\begin{gathered}
\dot{m}_{x}(r, \phi)=\text { uniform and } \dot{m}_{r}=\dot{m}_{\phi}=0 \mathrm{~kg} / \mathrm{s} \\
T_{f}(r, \phi)=T_{b, 0}=300 \mathrm{~K}
\end{gathered}
$$

(ii) Outlet boundary condition $\left(x=L_{T O T}\right)$ :

A zero pressure gradient condition was applied across the outlet boundary, and the outlet pressure was set as follows:

$$
P(r, \phi)=P_{a t m}
$$

(iii) Tube inner-wall surface boundary condition $\left(r=\mathfrak{R}_{i}\right)$ :

No-slip conditions were applied at the inside absorber tube wall:

$$
v_{r}=v_{\phi}=v_{x}=0
$$

(iv) External-wall surface boundary conditions $\left(r=\mathfrak{R}_{o}\right)$ :

Eq. (34) gives the external-wall surface boundary condition used for the non-uniform heat flux distributions expressed in terms of the concentrated base-level heat flux, $q_{s}^{\prime \prime}$.

$$
\begin{gathered}
q_{o,(m, n)}^{\prime \prime}=q_{s}^{\prime \prime} \sin \left[\frac{\pi}{\alpha} \phi\left(n-n_{i=1}+\frac{1}{2}\right)\right] \\
\text { for } m \in[1, M] \text { and } n \in\left[n_{i=1}, n_{i=1}+I\right)
\end{gathered}
$$

The concentrated base-level heat flux intensities used for indicative purposes in this study are $7.1 \mathrm{~kW} / \mathrm{m}^{2}, 14.2 \mathrm{~kW} / \mathrm{m}^{2}$ and $21.3 \mathrm{~kW} / \mathrm{m}^{2}$. This would depend on the concentration factor of the parabolic receiver and the applicable solar radiation level. Unless stated otherwise, the results shown are for $q_{s}^{\prime \prime}=7.1 \mathrm{~kW} / \mathrm{m}^{2}$. 


\subsection{Numerical procedure, grid analysis and model validation}

The governing equations in Eqs (27) - (29) were solved numerically, using the finite volume method described by Patankar [8], Ferziger and Perifi [29] and Versteeg and Malalasekera [30]. The computational domain, which consists of the tube model shown in Fig. 5 and the heat transfer fluid flowing inside the tube, was meshed with Hex 8 cells (hexahedron element with 8 vertices, 12 edges and bounded by 6 quadrilateral faces) and Wed6 cells (triangular prism element with 6 vertices, 9 edges, bounded by 2 triangular and 3 quadrilateral faces) structures by using the grid generation tool of the ANSYS Workbench. Hexahedral mesh structures give the highest solution accuracy, while triangular prism mesh structures resolve the boundary layers very efficiently [27]. The convective terms in the momentum and energy equations were discretised and solved using a second-order upwind scheme, and the standard SIMPLEC algorithm was used for the pressure-velocity coupling. The boundary conditions and material properties in ANSYS Fluent were modified to suit the case for the present study. The heat flux boundary conditions were applied according to the angular position of the boundary cell via user defined functions. The convergence criteria for the continuity and momentum equations and the energy equation were set so that the maximum residuals would be less than $10^{-7}$ and $10^{-9}$ respectively.

The thermal properties of the tube material and heat transfer fluid presented in Table 1 were assumed constant and independent of temperature except for the density $(\rho)$ of the fluid which was temperature-dependent expressed in Eq. (35) and the viscosity of the fluid also varied for the temperature range considered.

$$
\rho=\rho_{o}(1-\beta \Delta T)
$$


Table 1 Properties of the heat transfer fluid and tube model material.

\begin{tabular}{l|c|c}
\hline Property & $\begin{array}{c}\text { Fluid } \\
\text { (water) }\end{array}$ & $\begin{array}{c}\text { Solid } \\
\text { (steel) }\end{array}$ \\
\hline Density, $\rho_{o}\left(\mathrm{~kg} / \mathrm{m}^{3}\right)$ & 998.2 & 8030 \\
Specific heat, $c_{p}(\mathrm{~J} / \mathrm{kgK})$ & 4182 & 502.48 \\
Thermal conductivity, $k(\mathrm{~W} / \mathrm{mK})$ & 0.61 & 16.27 \\
Inlet fluid temperature $(\mathrm{K})$ & 300 & - \\
\hline
\end{tabular}

Here, $\rho_{o}$ is the base density at the reference temperature of $300 \mathrm{~K}, \Delta T$ is the temperature change from the reference temperature and $\beta=0.000195 \mathrm{~K}^{-1}[19]$.

A series of grid independence studies were conducted in terms of the outlet temperature rise of the heat transfer fluid for an inlet Reynolds number range of 130 to 2200 . It was ensured that the grid was sufficiently fine in order not to have a significant effect on the numerical simulation results. For demonstration purposes, the grid refinement test results conducted at an inlet Reynolds number of 202 for a $\alpha=360^{\circ}$ fully uniform heat flux distribution is presented in Table 2. Also, energy balance checks of the heat transfer model were performed, which gave an average percentage error of $<1 \%$ of the resultant heat flux distributions on the tube model.

Table 2 Grid refinement test results.

\begin{tabular}{ccc}
\hline $\begin{array}{c}\text { Number of } \\
\text { numerical } \\
\text { cells }\end{array}$ & $\begin{array}{c}\text { Bulk fluid } \\
\text { outlet } \\
\text { temperature }\end{array}$ & $\begin{array}{c}\text { Change in } \\
\text { temperature } \\
\text { due to } \\
\text { refinement }(\mathbf{K})\end{array}$ \\
\hline 145688 & 397.4844 & - \\
465854 & 397.3815 & 0.102 \\
481327 & 397.3763 & 0.005 \\
508028 & 397.3747 & 0.002 \\
525147 & 397.3648 & 0.009 \\
540108 & 397.3563 & 0.008 \\
\hline
\end{tabular}

A number of validations were done to check the correctness of the simulation results of the absorber tube model. The first check was performed by comparing the heat loss (Fig.7) as a 
function of the absorber tube temperature from the simulation results and that of the experimental results for the heat loss tests of the Schott's 2008 PTR70 parabolic trough receiver performed by Burkholder and Kutscher [31] at the NREL HCE Heat Loss Test Stand. In this test, electric resistance heaters on the inside of the heat collector element (HCE) were used to bring the absorber tube surface up to desired test temperatures. The thermal emittance of the absorber was determined from the measured heat losses and temperatures. The heat loss results were validated from the HCE in a solar field estimated from the Forristall's parabolic trough collector model [17]. Therminol VP-1 was used as the heat transfer fluid. The tested Schott's receiver had a length of $4.06 \mathrm{~m}$, with inner and outer diameters of $0.066 \mathrm{~m}$ and $0.07 \mathrm{~m}$, and a glass envelope of inner and outer diameters of $0.115 \mathrm{~m}$ and $0.12 \mathrm{~m}$. The data used for the model validation of this study are also given in Table 3. Figs 7 and 8 show that the numerical model results and that of the experimental tests results are in good agreements and almost all the values are within the experimental error bars of $7 \%$. In Fig. 8, the model results indicated better prediction of the glass temperature at lower absorber temperature. However, at higher absorber temperature, it over- predicted the glass temperature and this could be attributed to the inaccurate emittance values of the glass determined form the experimental heat loss measurements under steady-state condition. The emittance determined through the heat loss measurements cannot guarantee accurate glass temperature due to the variation of the optical properties of the HCE with temperature and the effects of anti-reflection coating on the glass which were not considered in the present model. 
Table 3 Parameters for the Schott PTR70 Lab test [23] used for the model validation.

\begin{tabular}{l|l}
\hline Parameter & Value \\
\hline Heat collector Element length & $4.06 \mathrm{~m}$ \\
Absorber inner diameter $\left(D_{i}\right)$ & $0.066 \mathrm{~m}$ \\
Absorber outer diameter $\left(D_{o}\right)$ & $0.070 \mathrm{~m}$ \\
Glass inner diameter $\left(D_{i, g}\right)$ & $0.115 \mathrm{~m}$ \\
Glass cover external diameter $\left(D_{o, g}\right)$ & $0.120 \mathrm{~m}$ \\
Glass transmittance $\left(\tau_{g}\right)$ & 0.00 \\
Glass reflectance $\left(\rho_{g}\right)$ & 0.11 \\
Incident angle $\left(\phi_{\text {in }}\right)$ & $0^{\circ}$ \\
Ambient temperature & $23{ }^{\circ} \mathrm{C}$ \\
Selective coating emissivity & $\varepsilon=0.062+2 \times 10^{-7} T$ \\
\hline
\end{tabular}

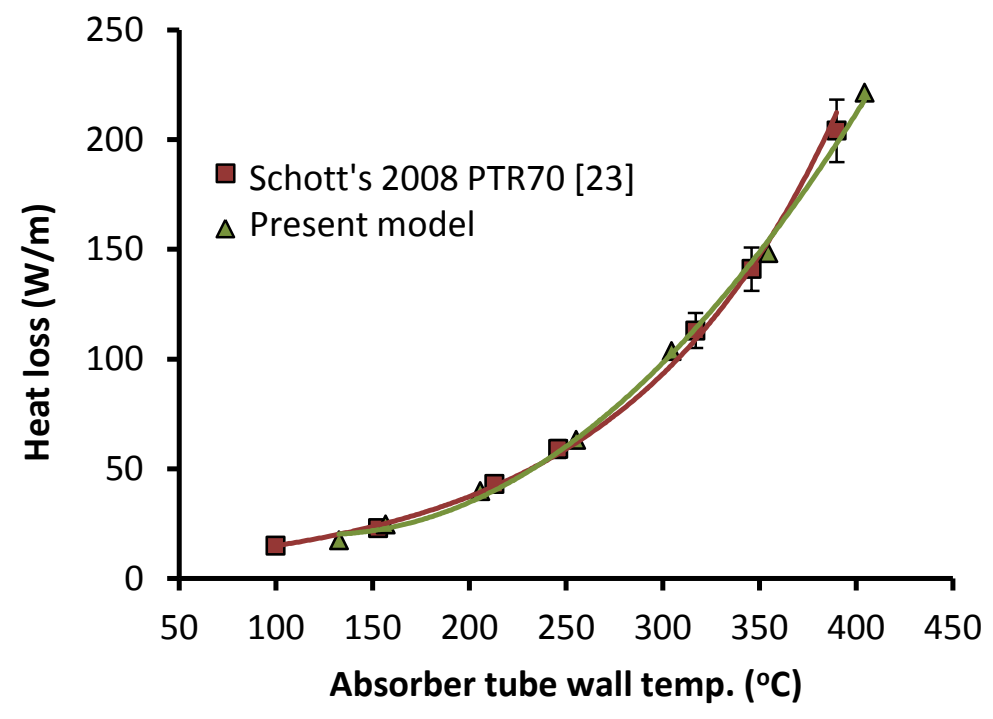

Fig. 7 Variation of the collector heat loss with the absorber tube temperature.

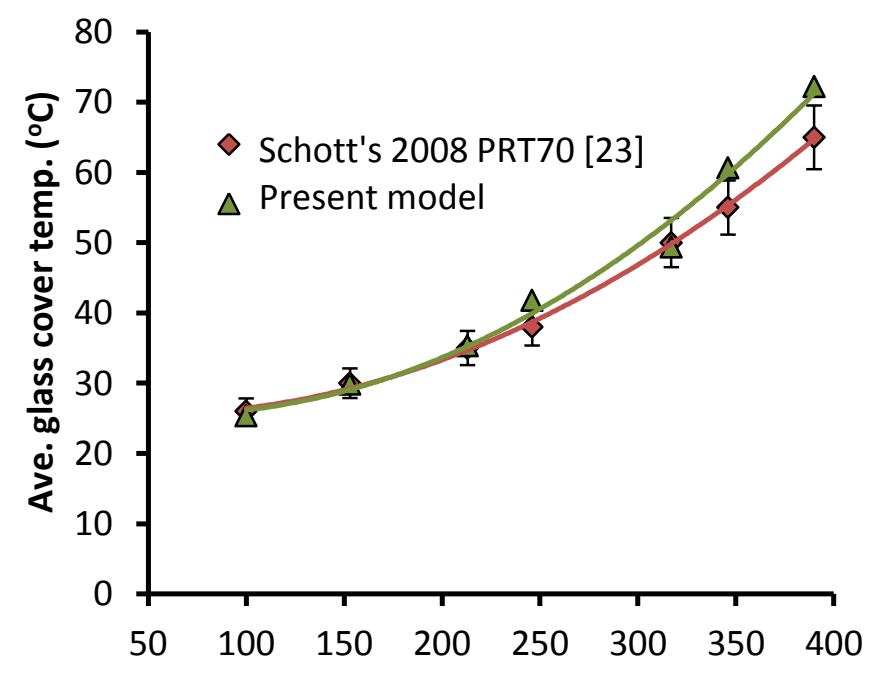

Ave. absorber tube temperature $\left({ }^{\circ} \mathrm{C}\right)$

Fig. 8 Variation of the average glass cover temperature with the absorber tube temperature. 
The second check was performed by comparing the model results for the collector efficiency and heat loss as functions of the collector operating temperature respectively and that of the SANDIA final test results for the Schott's HCE on a LS-2 collector module [23]. The Schott HCE consists of an absorber tube with outer diameter of $0.07 \mathrm{~m}$ coated with a high absorptance cermet selective coating and a Pyrex glass tube with outer diameter of $0.125 \mathrm{~m}$ and vacuum in the annulus to minimize convection heat loss. The data used for the model validation are given in Table 4. Syltherm 800 liquid oil was used as the heat transfer fluid and the thermal properties were obtained from [32]. As it could be expected, the collector efficiency decreased and the heat losses increased with an increase in the fluid temperature due to increase in convection, conduction and radiation heat losses. Figs 9 and 10 showed that the model results of the current study, the experimental tests results and that of the curve fit for LS-2/ UVAC2 HCE respectively are in good agreements and most of the values for the case of the collector efficiency are within the experimental error bars of $3 \%$. However, the model results over-predicted the collector efficiency. In Fig. 10, the model results for the heat loss and that of the curve fit for LS-2/UVAC2 HCE indicated some discrepancies with the experimental results (shown with error bars of 10\%), especially at higher operating temperatures. The discrepancies could be due to variation of the optical properties of the HCE with temperature, the uncertainty in measuring small temperature change across the HCE, the assumptions of negligible heat conduction at the ends of HCE, possible misalignment between HCE and the collector [17] and the uncertainties due to the thermal properties of the heat transfer fluid and the empirical correlations used in determining the heat transfer coefficients. 
Table 4 Parameters for the Schott HCE on the LS-2 Collector [31] used for the model validation.

\begin{tabular}{l|l}
\hline Parameter & Value \\
\hline Ave. Normal incidence pyrheliometer reading & $934.30-1051.08 \mathrm{~W} / \mathrm{m}^{2}$ \\
Ave. Wind speed & $3.1-13.8 \mathrm{MPH}$ \\
Concentrator length $(L)$ & $7.8 \mathrm{~m}$ \\
Collector aperture $(W)$ & $5 \mathrm{~m}$ \\
HCE length & $4 \mathrm{~m}$ \\
Ave. ambient temperature & $3.52-14.67{ }^{\circ} \mathrm{C}$ \\
Average flow rate & $9.95-14.68 \mathrm{gal} / \mathrm{min}$ \\
Absorber inner diameter $\left(D_{i}\right)$ & $0.066 \mathrm{~m}$ \\
Absorber outer diameter $\left(D_{o}\right)$ & $0.070 \mathrm{~m}$ \\
Glass inner diameter $\left(D_{i, g}\right)$ & $0.109 \mathrm{~m}$ \\
Glass outer diameter $\left(D_{o}\right)$ & $0.12 \mathrm{~m}$ \\
Receiver absorptance $(\alpha)$ & 0.96 \\
Glass transmittance $\left(\tau_{g}\right)$ & 0.935 \\
Selective coating emissivity & $\varepsilon=0.000327 T-0.065971$ \\
Incident angle $\left(\phi_{i n}\right)$ & $0^{\circ}$ \\
\hline
\end{tabular}

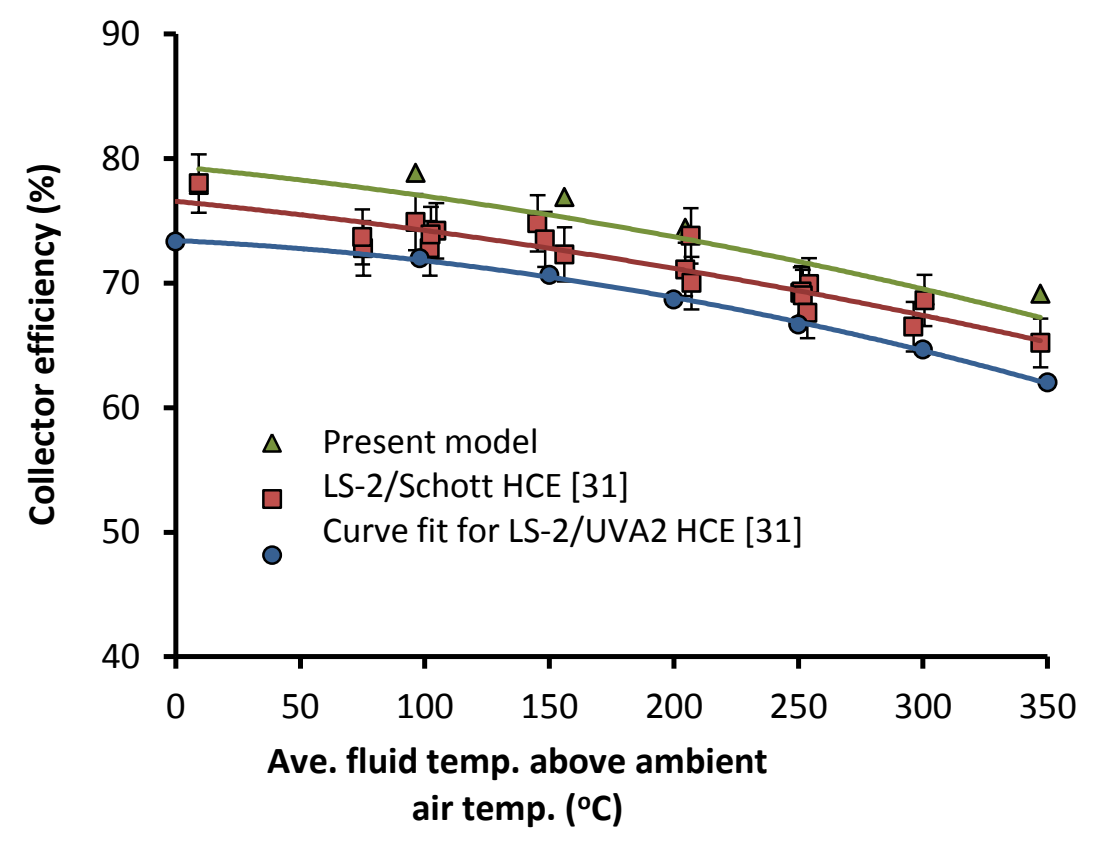

Fig. 9 Variations of the collector efficiency with the average fluid temperature above ambient air temperature. 


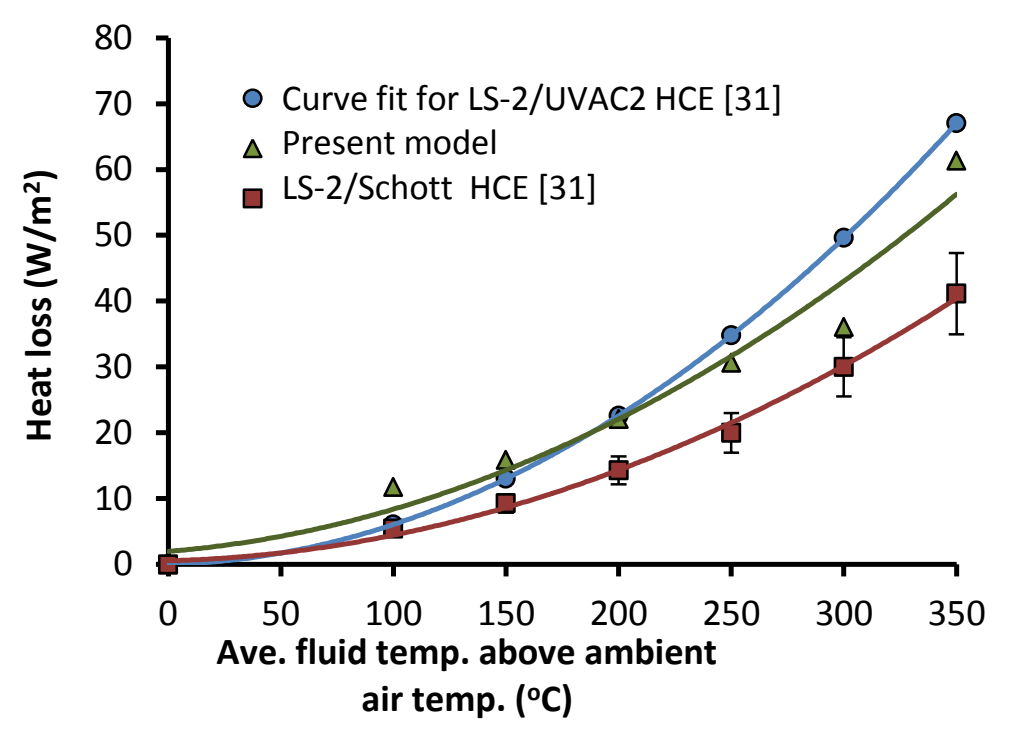

Fig. 10 Variations of the collector heat loss with the average fluid temperature above ambient air temperature.

The model was also validated by comparing the simulation results with the NREL model developed by Forristall [17] and the experimental tests results for a LS-2 solar collector module placed on the AZTRAK rotating platform at the Sandia National Laboratory (SNL). Detailed information on the AZTRAK testing and the tests results can be found in Dudley et al. [33]. The Sandia test and NREL model considered both on-sun and off-sun conditions and the heat collection element $(\mathrm{HCE})$ with vacuum intact (pressure in the annulus: $\simeq 0.013 \mathrm{~Pa}$ ) and vacuum lost (annulus filled with ambient air) and the absorber tube with no glass cover. The absorber tubes were coated with black chrome and cermet selective coatings and buoyancy effects were not considered in these tests. The present model was validated for the case of on-sun, vacuum and no vacuum conditions and the cermet selective coatings on the absorber tube. The experimental data for the LS-2 solar collector module used for the model validation are shown in Table 5. Syltherm 800 liquid oil was used as the heat transfer fluid and the thermal properties for the fluid were obtained from [32]. The cermet coating had better thermal performance than the black chrome at high temperatures and does not oxidize in the event of vacuum lost [33]. Figs 11 and 12 indicate an increase in heat losses and a 
decrease in the collector efficiency respectively, with an increase in the fluid temperature due to the increase in convection, conduction and radiation heat losses for both cases of vacuum and air in the annulus. Also, the increase in heat losses and decrease in efficiency were more pronounced for the case with ambient air in the annulus. Figs 11 and 12 show that the model results are in good agreements with the experimental tests results and that of the NREL model and most of the values for the collector efficiency are within the experimental error bars of $3 \%$. In Fig. 12, the model results and that of the NREL model indicated some discrepancies with the experimental results (shown with error bars of $10 \%$ ), especially for the case with air in the annulus. The discrepancy could be due to the uncertainties from empirical correlations used for the heat transfer coefficients and the assumption that the glass cover is opaque to infrared radiation with gray and diffuse surfaces [34]. The errors could also be due to the thermal loss through the steel support bracket and optical effects such as the mirror alignment, aberration in mirrors and tracking system errors [17], which were not considered in the present model.

Table 5 Parameters for the SEGS LS-2 Solar Collector tests by Dudley et al. [33] and Forristall [17] used for the model validations.

\begin{tabular}{l|l}
\hline Parameter & Value \\
\hline Direct solar irradiation & $880.6-982.3 \mathrm{~W} / \mathrm{m}^{2}$ \\
Wind speed & $0.1-4.2 \mathrm{~m} / \mathrm{s}$ \\
Concentrator length $(L)$ & $7.8 \mathrm{~m}$ \\
Collector aperture $(W)$ & $5 \mathrm{~m}$ \\
Concentrator rim angle & $70^{\circ}$ \\
HCE length & $4 \mathrm{~m}$ \\
Ambient temperature & $21.2-31.1^{\circ} \mathrm{C}$ \\
HTF volumetric flow rate & $47.7-56.31 / \mathrm{min}$ \\
Absorber inner diameter $\left(D_{i}\right)$ & $0.066 \mathrm{~m}$ \\
Absorber outer diameter $\left(D_{o}\right)$ & $0.070 \mathrm{~m}$ \\
Glass inner diameter $\left(D_{i, g}\right)$ & $0.109 \mathrm{~m}$ \\
Glass outer diameter $\left(D_{o, g}\right)$ & $0.115 \mathrm{~m}$ \\
Receiver absorptance $(\alpha)$ & 0.96 \\
Glass transmittance $\left(\tau_{g}\right)$ & 0.935 \\
Glass envelope reflectance $(\rho)$ & 0.045 \\
Selective coating emissivity & $\varepsilon=0.000327 T-0.065971$ \\
Selective coating solar absorptivity & 0.92 \\
Concentrator emissivity & 0.97 \\
Incident angle $\left(\phi_{i n}\right)$ & $0^{\circ}$ \\
\hline
\end{tabular}




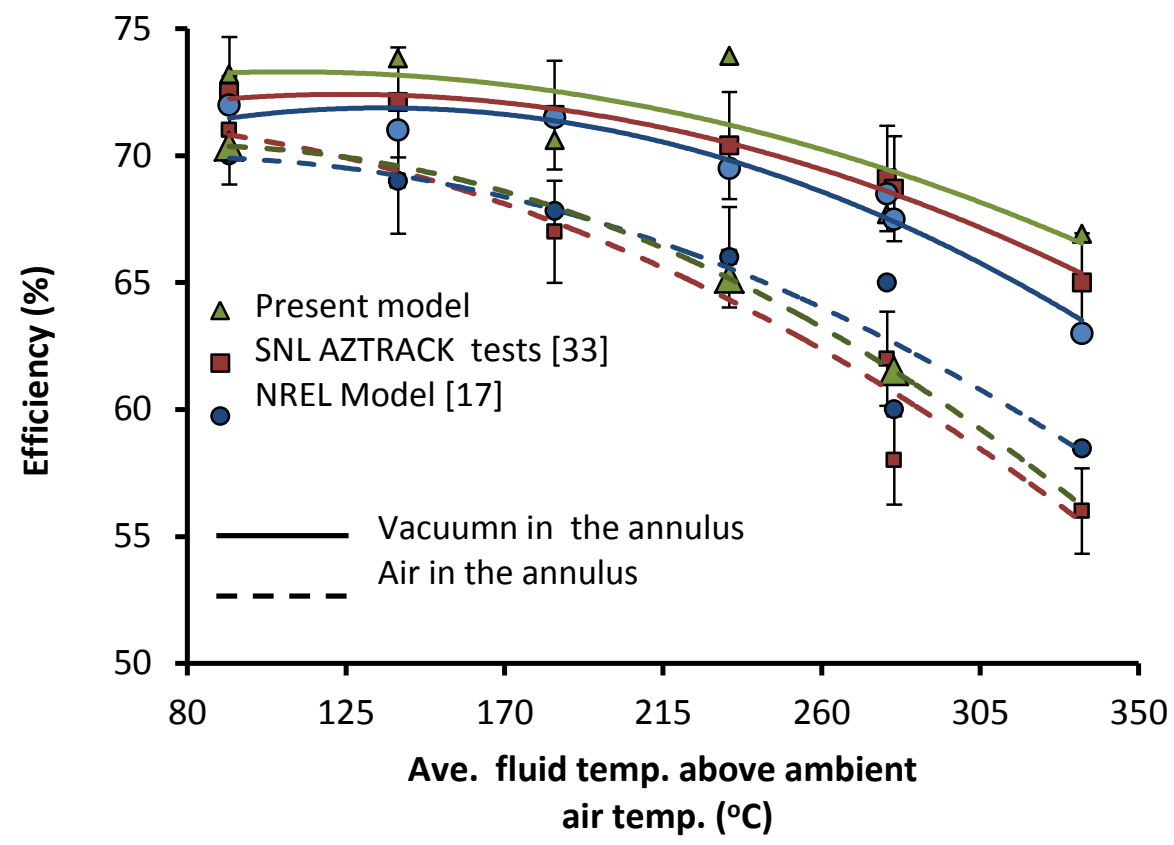

Fig. 11 Variations of the collector efficiency with the average fluid temperature above ambient air temperature.

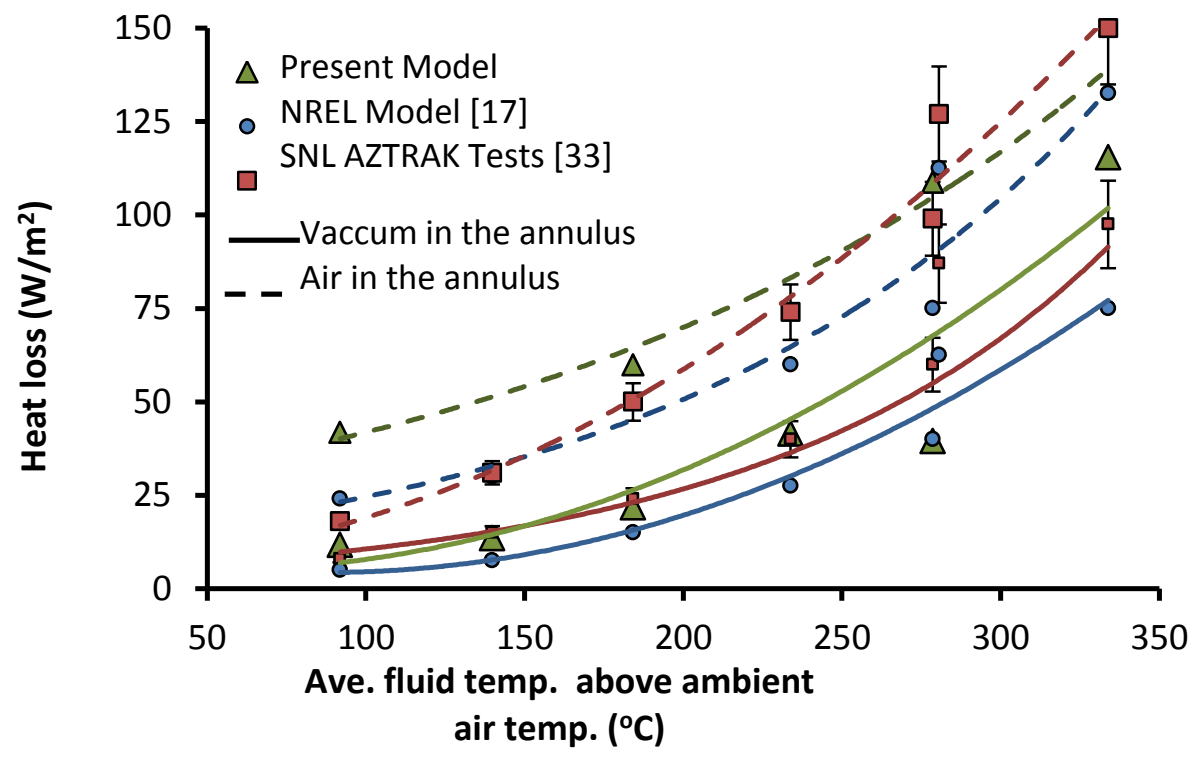

Fig. 12 Variation of the collector heat loss with the average fluid temperature above ambient air temperature.

The model was further validated for verifying the case of absorber tube with buoyancy driven secondary flow by comparing the calculated axial local Nusselt number with results and correlations published by other researchers. These include the Shah correlation [35] in Eq. 
(36) and an experimental correlation [36] in Eq. (37) for the laminar flow mixed convection under uniform heat flux boundary conditions.

$$
\begin{gathered}
N u(x)=1.953\left(\operatorname{Re}_{D_{i}} \operatorname{Pr} \frac{D_{i}}{x}\right)^{1 / 3} \text { for } \operatorname{Re}_{D_{i}} \operatorname{Pr} \frac{D_{i}}{x} \geq 33.3 \\
N u(x)=\left[4.364^{3}+1+\left(2.117\left(\operatorname{Re}_{D_{i}} \operatorname{Pr} \frac{D_{i}}{x}\right)^{1 / 3}-0.6\right)^{3}\right]^{1 / 3}
\end{gathered}
$$

Here $\operatorname{Re}_{D i}$ is based on the inner diameter of the tube: $\operatorname{Re}_{D_{i}}=\rho \bar{v} D_{i} / \mu$. Fig. 13 shows the calculated axial local Nusselt numbers with buoyancy driven secondary flow compared with the Nusselt number correlations in Eqs (36) and (37) for an inlet Reynolds number of 800. It shows that the axial local Nusselt number results obtained from the numerical are in good agreement with the correlations and that the same trends were obtained. For the mass flow rate shown at $x / D_{i} \approx 30$ for instance, the numerical results have a deviation of $15 \%$ in terms of Eq. (36) and $18 \%$ in terms of Eq. (37), while at $\mathrm{x} / D_{i} \approx 160$ these deviations are $3 \%$ and $10 \%$ respectively. The deviation could be due to the difference in the thermal boundary conditions employed for the correlations and that buoyancy effects are dependent on the wall thermal boundary conditions [13]. Also, a perfect reproduction of the actual experimental boundary conditions is difficult since the detailed experimental set-up information is not readily available. 


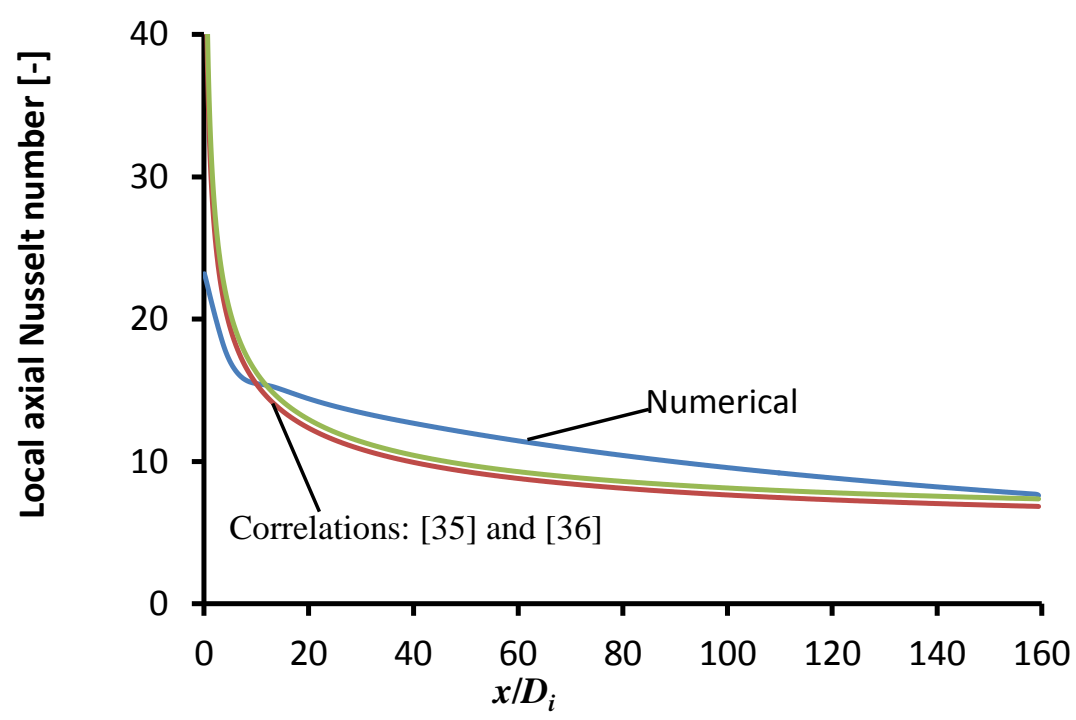

Fig. 13 Axial local Nusselt numbers for an inlet Reynolds number 800 with buoyancy driven flow for uniform heat flux.

\section{Numerical simulation results and discussion}

\subsection{Temperature contours for the non-uniform heat flux distributions boundaries}

Fig 14 shows the temperature contours for $\alpha=140^{\circ}, 180^{\circ}, 220^{\circ}$ and $260^{\circ}$ respectively. The flow direction is indicated by the arrow. As expected, it can be observed that the outer-wall surface temperatures increase in the flow direction. The lower region at the outlet is the warmest, as shown by the red shade. As the heat flux distributions span increase, a larger portion of the tube's outer surface is at temperatures close to the peak temperature. The temperatures in the upper regions are lower because there is little (or no significant) incident heat flux in those locations. These temperature variations result in density differentials within the heat transfer fluid and these results in buoyancy-driven secondary flow, which enhances the internal mixing of the heat transfer fluid in laminar or weak turbulent flow regime.

The non-uniform tube-wall temperature variation over the circumferential surface of the absorber tubes in Fig.14 is plotted in Fig.15 for an inlet Reynolds number of 1100. It indicates the length-wise averaged outer surface temperature profiles according to section numbers $n=1$ to 36 , for $\alpha=140^{\circ}, 180^{\circ}, 220^{\circ}$ and $260^{\circ}$ respectively. It shows that the outer- 
wall temperature increases with an increase in the heat flux span due to an increase in the circumferential surface of the absorber tube exposed to the incident heat flux. The maximum outer-wall temperature occurs at the lower region of the tube which corresponds to the position where the heat flux distribution reach its peak and decreases towards the upper region the tube with a little incident heat flux.

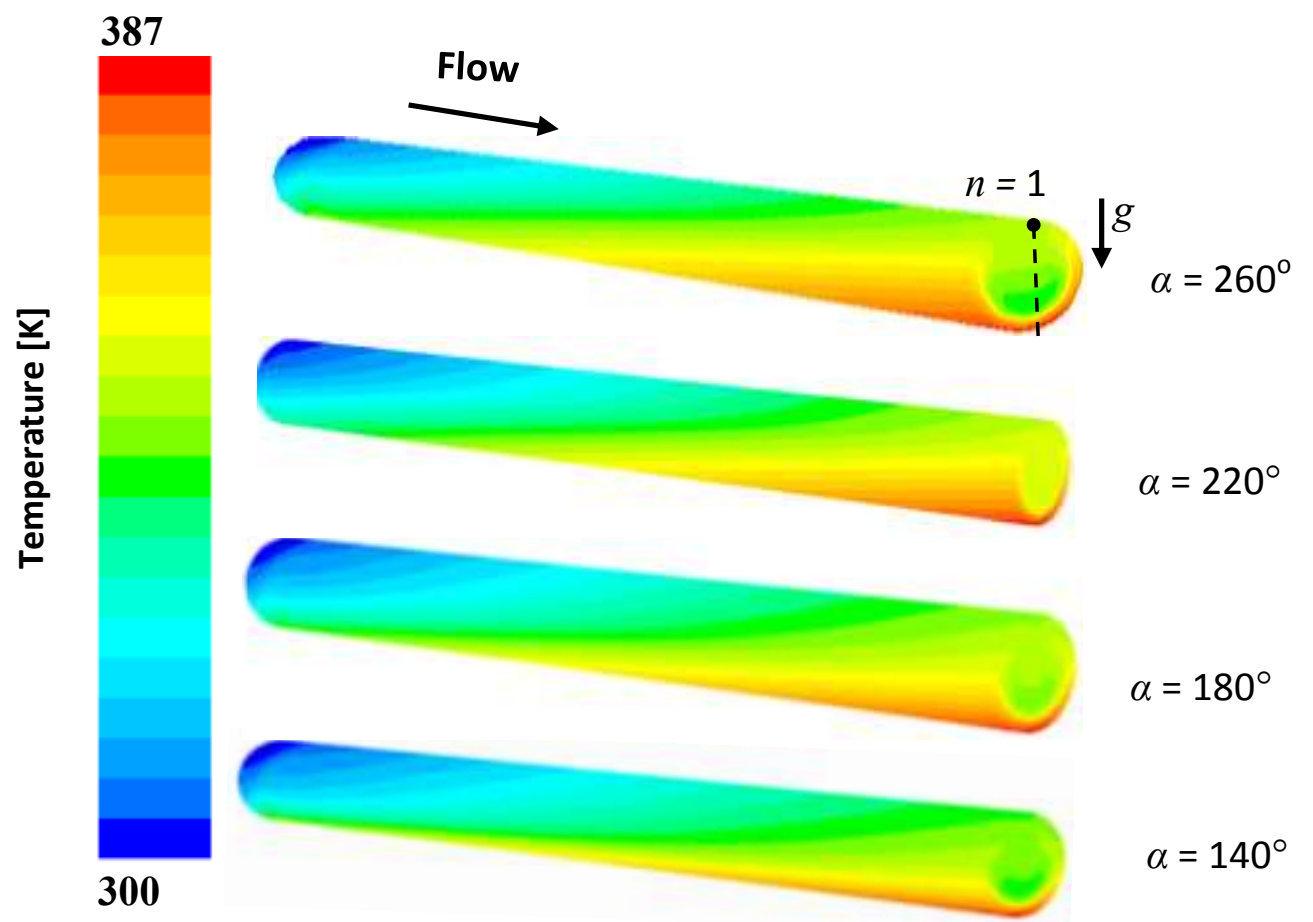

Fig.14 Temperature contours for the circumferential sinusoidal non-uniform heat flux distributions. 


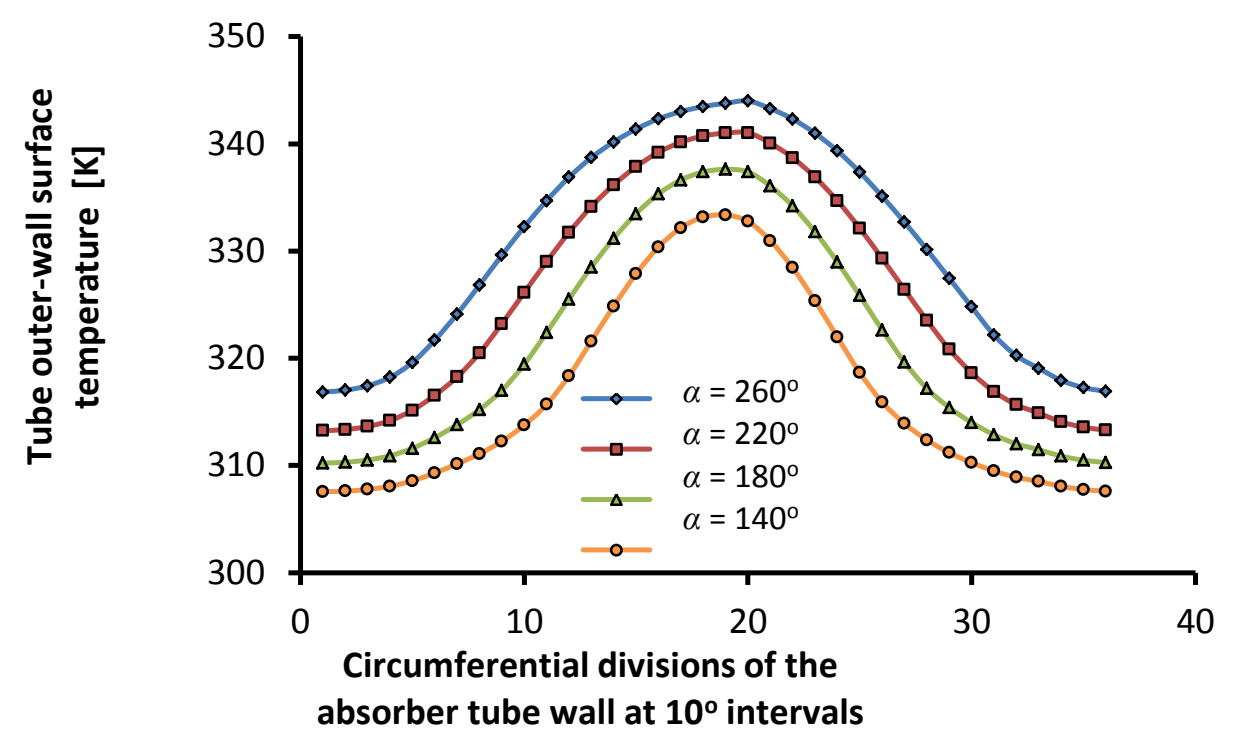

Fig. 15 Non-uniform tube-wall temperature profiles for a sinusoidal non-uniform heat flux distributions for $\mathrm{Re}=$ 1100 and $q_{s}^{\prime \prime}=7.1 \mathrm{~kW} / \mathrm{m}^{2}$.

\subsection{Fluid flow velocity and temperature distributions}

Fig 16 shows the in-plane fluid velocity vectors (Fig.16a) as well as the fluid and wall temperature distributions (Fig.16b) at the outlet of the absorber tube for inlet Reynolds numbers of 130, 200 and 500. It can be seen that the velocity distributions are different for each Reynolds number case, indicating different mixing intensities within the heat transfer fluid. The denser colder fluid descends to the lower region of the tube along the vertical centre of the tube and less dense warmer fluid ascends along the tube wall. Due to this, counter-rotating transverse vortices are produced that are superimposed on the forcedconvection flow, as also noted by Ghajar and Tam [13] and by Sadik et al. [37]. The overall effect of this phenomenon is improved mixing of the heat transfer fluid, thereby increasing the heat transfer coefficients compared to cases without buoyancy effects in the laminar or weak turbulent flow regime [38]. It can also be seen that as the Reynolds number increases the temperature gradients decrease. 


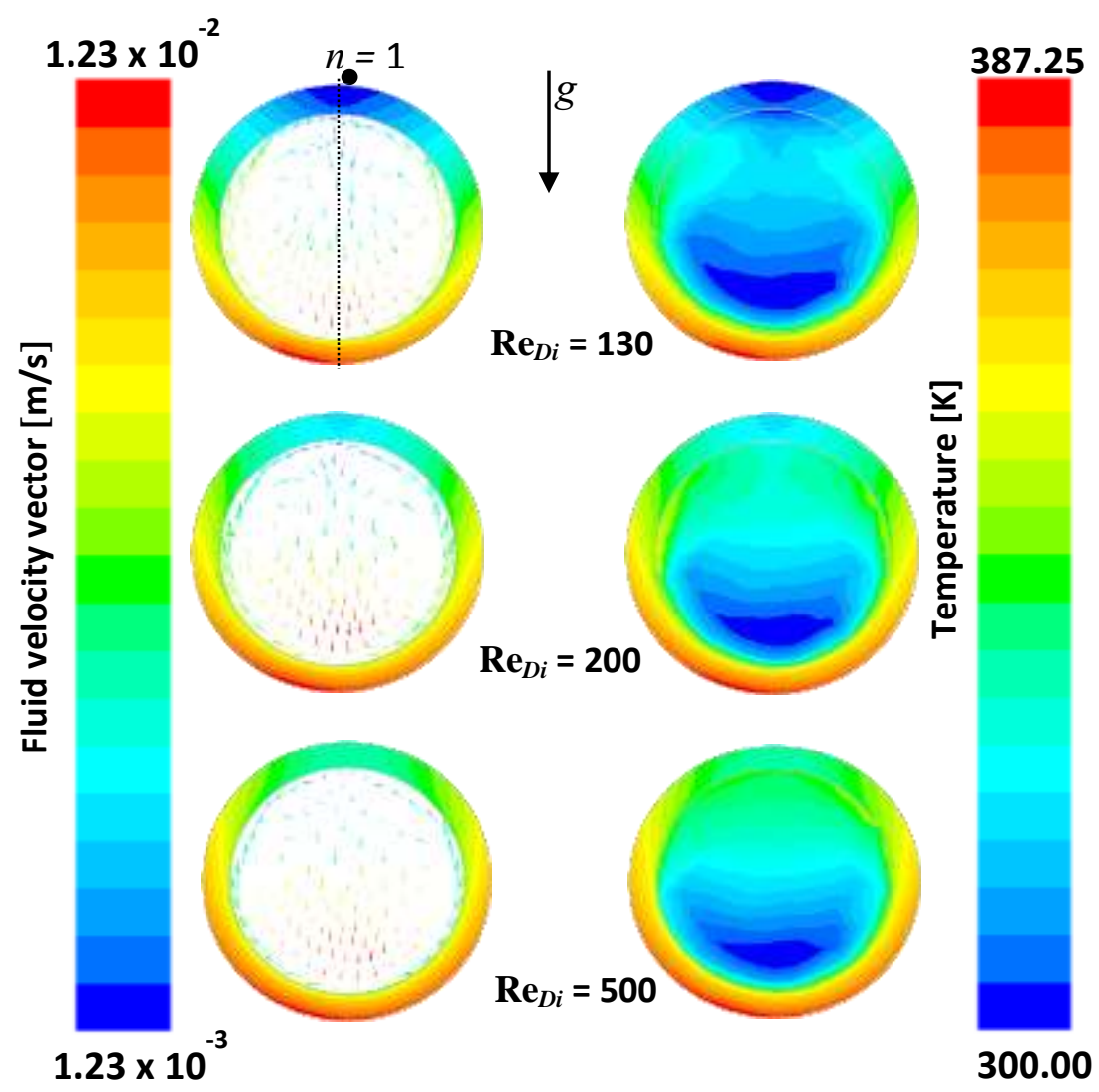

Fig. 16 (a) Fluid flow velocity and (b) temperature distribution in the fluid for a sinusoidal non - uniform heat flux distribution at $q_{s}^{\prime \prime}=7.1 \mathrm{~kW} / \mathrm{m}^{2}$ at different Reynolds numbers.

\subsection{Heat transfer coefficients for different base-levels heat flux intensities}

In order to demonstrate the heat transfer enhancement due to buoyancy effects, two scenarios will now be considered at different inlet Reynolds numbers $\left(\operatorname{Re}_{D i}\right)$ for three different baselevel heat flux intensities for $\alpha=260^{\circ}$. In the first scenario, buoyancy-driven flow is ignored (presented in Fig. 17), while in the second scenario it is included (presented in Fig. 18).

In Fig. 17 as expected, the internal heat transfer coefficient increases with the Reynolds number since the flow is not yet fully developed. It can be seen that there is no significant difference in the average internal heat transfer coefficients for different base-level heat flux intensities. This implies that for this scenario, the average internal heat transfer coefficient is 
also independent of the heat flux distribution profiles (for instance uniform versus nonuniform).

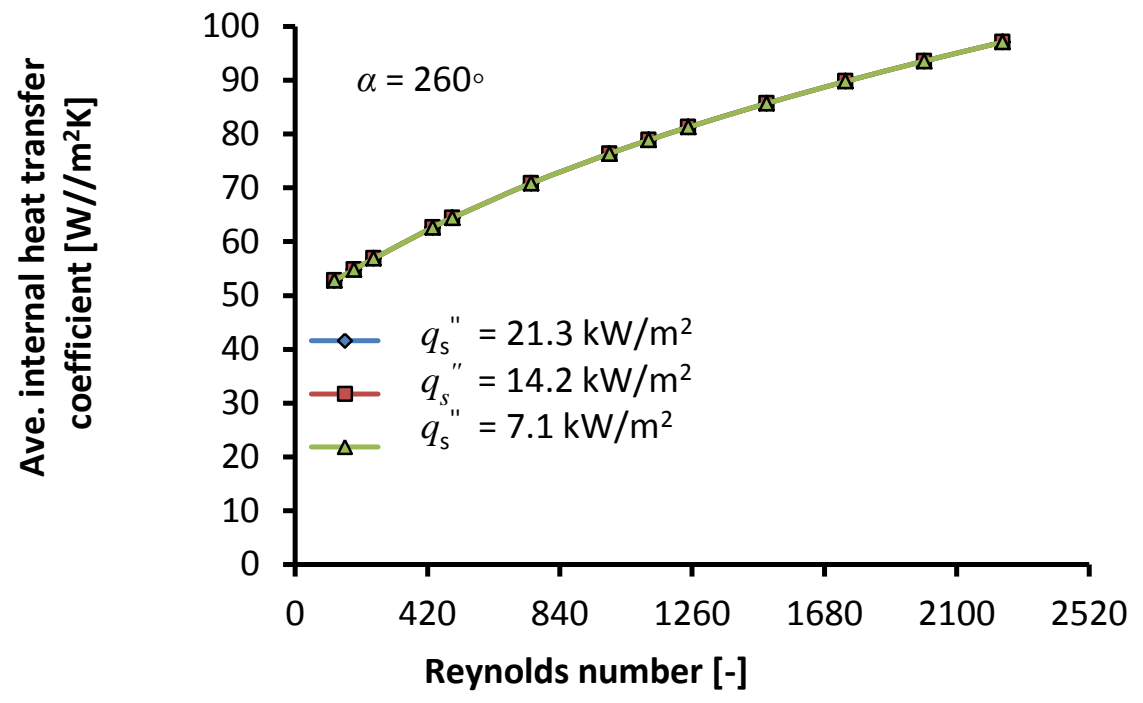

Fig. 17 Average internal heat transfer coefficients for a sinusoidal non-uniform heat flux distributions for different base-level intensities with no secondary flow.

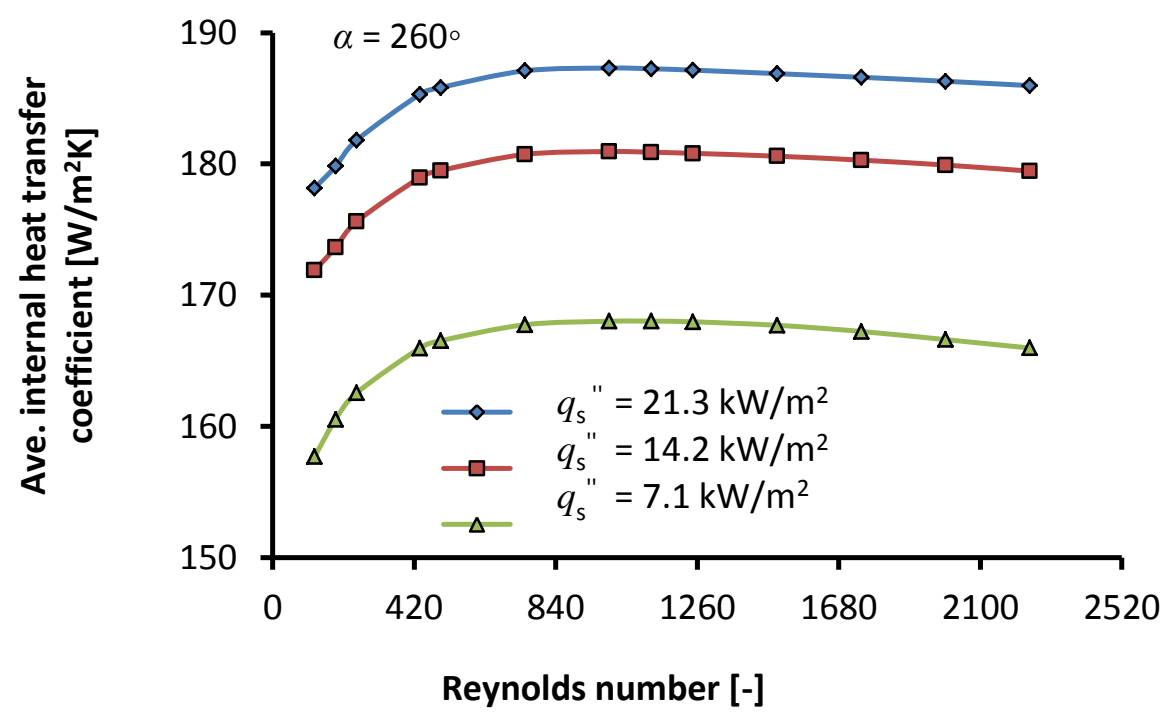

Fig. 18 Average internal heat transfer coefficients for a sinusoidal non-uniform heat flux distributions for different base-level intensities with secondary flow present.

In Fig. 18, it can be seen that there is a significant enhancement in the average internal heat transfer coefficients with an increase in the heat flux intensities. This is attributed to the improved mixing of the heat transfer fluid due to an increase in the buoyancy-driven 
secondary flow resulting from an increase in the fluid density gradient arising from the temperature gradient between the fluid and the heated tube-wall surface. This agrees with the experimental report by Mohammed and Salman [14].

The results in Figs 17 and 18 underscore the internal heat transfer enhancement due to buoyancy-induced secondary flow effects on the internal heat transfer coefficients of a horizontal circular absorber tube, due to variations of the heat flux intensity and the circumferential non-uniform heat flux distributions profiles. For $\alpha=260^{\circ}$ the average internal heat transfer coefficient for the base-level non-uniform heat flux intensities of $21.2 \mathrm{~kW} / \mathrm{m}^{2}$, $14.2 \mathrm{~kW} / \mathrm{m}^{2}$ and $7.1 \mathrm{~kW} / \mathrm{m}^{2}$ is found to be $163 \%, 154 \%$ and $135 \%$ respectively higher than when the buoyancy-induced secondary flow is neglected in Fig. 17. This trend is in line with the experimental results by Mori et al. [39], who investigated buoyancy effect in a horizontal tube under uniform heat flux condition.

\subsection{Heat transfer coefficients for different circumferential spans of non-uniform heat}

\section{flux boundaries}

The impact of different heat flux spans of $\alpha=140^{\circ}, 180^{\circ}, 220^{\circ}$ and $260^{\circ}$ for different inlet Reynolds numbers are shown in Figs 19 and 20 for a scenario without and with buoyancy effects respectively. As expected the average internal heat transfer coefficients increases with the Reynolds number, irrespective of whether buoyancy is considered. Without buoyancy effects there is no significant difference in the internal heat transfer coefficients for different angle spans (Fig 19). As before when, however, buoyancy effects are present (Fig 20), there is a significant increase in the average internal heat transfer coefficient as the heat flux circumferential span is increased. This mirrors the findings from Fig 18, and is mainly due to an increase in the effective heat input rate (W) into the tube as a result of an increase in the circumferential surface of the tube exposed to the incident heat flux. It is found that between 
$R e_{D i}=300$ and 1300 , the average internal heat transfer coefficients increases by $20 \%$ and $15 \%$ respectively, between $\alpha=140^{\circ}$ and $260^{\circ}$.

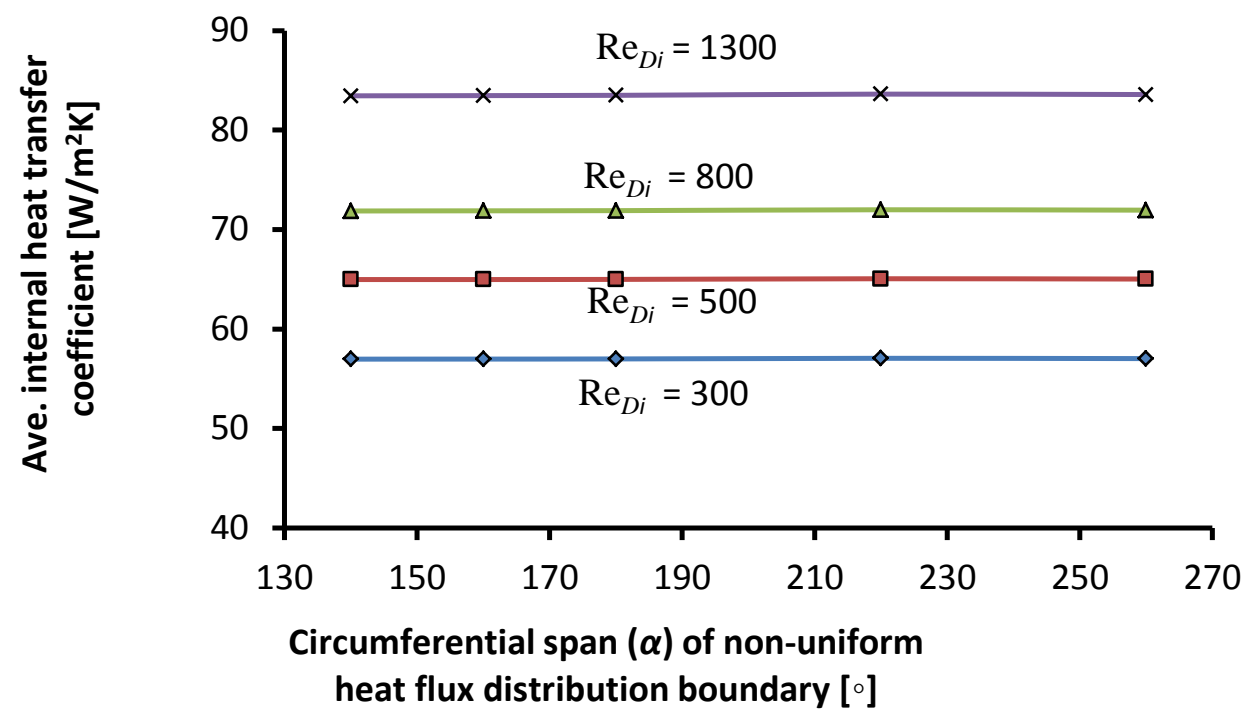

Fig. 19 Average internal heat transfer coefficient for different circumferential spans of sinusoidal non-uniform heat flux boundaries no with secondary flow.

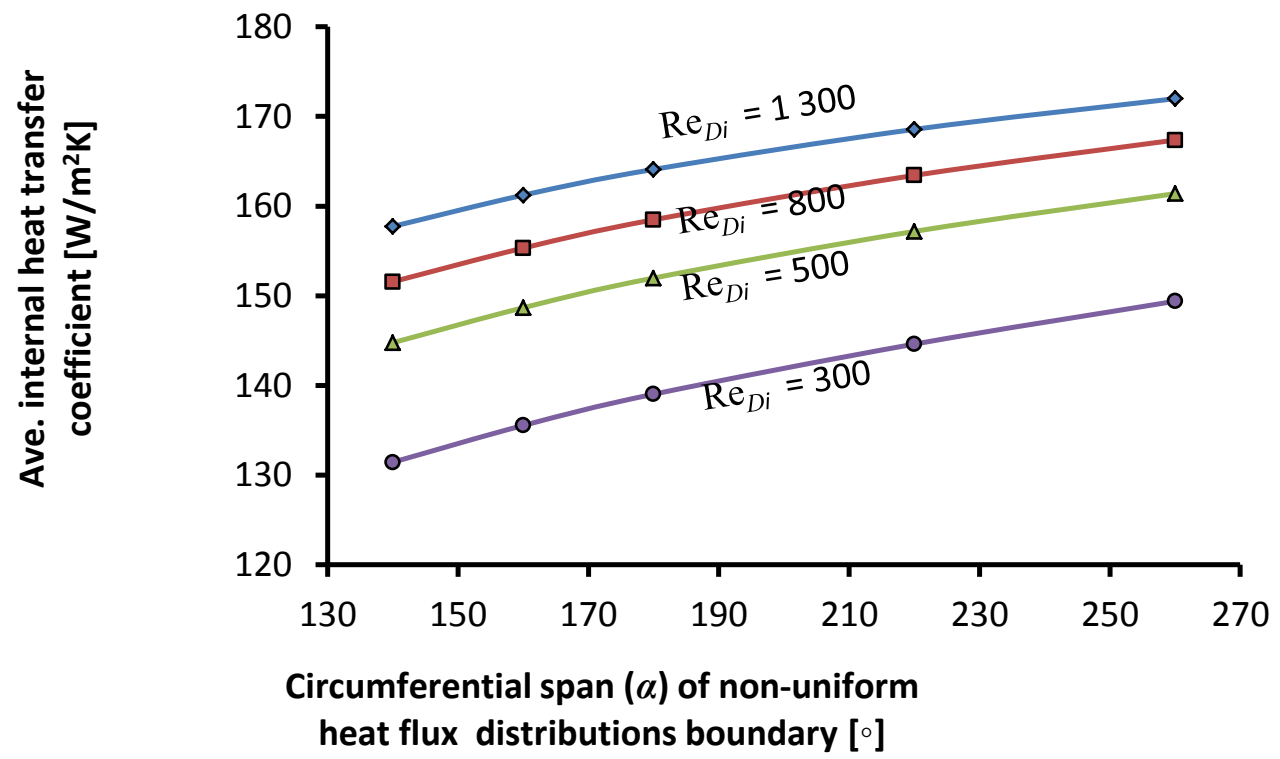

Fig. 20 Average internal heat transfer coefficient for different circumferential spans of sinusoidal non-uniform heat flux boundaries with secondary flow.

The impact of the buoyancy effect and the heat flux intensity on the axial local internal heat transfer coefficients (based on Eq. 20) are shown in Fig. 21 for $\alpha=260^{\circ}$ with base-level heat 
flux intensities of $7.1 \mathrm{~kW} / \mathrm{m}^{2}$ and $14.3 \mathrm{~kW} / \mathrm{m}^{2}$ for an inlet Reynolds number of 1100 . In this figure a comparison is made between the axial local heat transfer coefficients where buoyancy effects are considered (shown with the broken lines) and where it was neglected (solid lines). With buoyancy effects, the axial local heat transfer coefficients were greater by up to $128 \%$ and $144 \%$ (for the two base-level heat flux intensities respectively) between $x / D_{i} \approx 1.0$ and 98 , compared to the scenario without buoyancy effects. For both scenarios the highest heat transfer coefficients are present at the tube inlet where the thermal boundary layer was at its thinnest. As the flow becomes more developed and the thermal boundary layer becomes thicker, the heat transfer coefficient decreases. At $x / D_{i}=7$, the change in the heat transfer coefficients gradient could be due to the slight increase in the heat transfer coefficient at the point where the flow tends to depart from the region, where the influence of the hydrodynamic and thermal boundary layer effect could be insignificant.

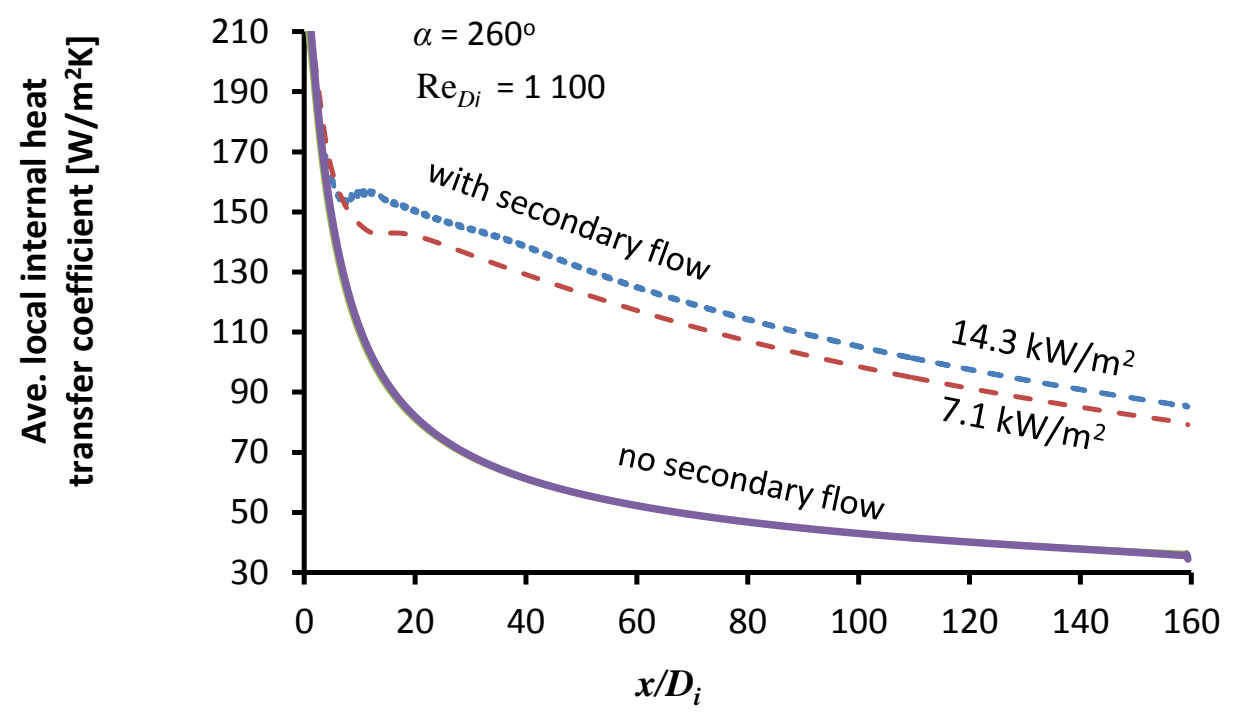

Fig. 21 Average axial local internal heat transfer coefficients for a sinusoidal non-uniform heat flux distributions at an inlet Reynolds number of 1100 . 


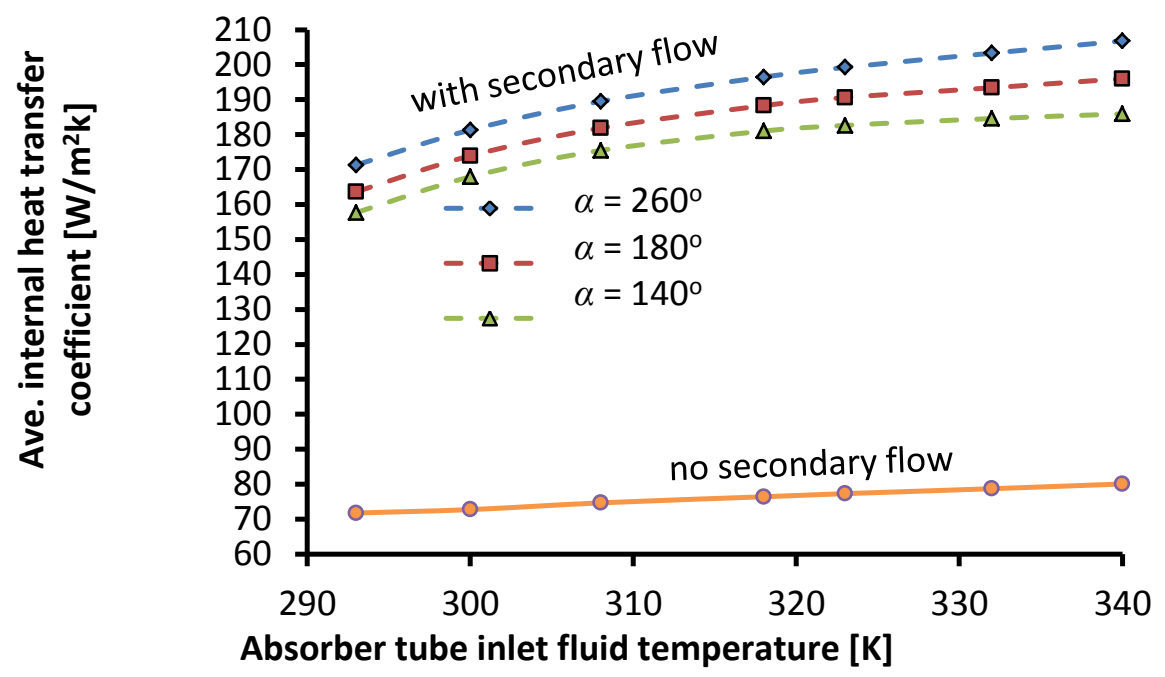

Fig.22 Variation of average internal heat transfer coefficient for an absorber tube at different heat transfer fluid inlet temperature.

Fig.22 indicates the impact of the inlet fluid temperature on the average internal heat transfer coefficient with the absorber tube for the heat flux spans of $\alpha=140^{\circ}, 180^{\circ}$ and $260^{\circ}$. For these heat flux span cases considered, where buoyancy effect is present, the average internal heat transfer coefficients are up to $132 \%, 144 \%$ and $158 \%$ higher respectively than when it was neglected (pure forced convection). This indicates a very high significant internal heat transfer enhancement due to buoyancy-driven secondary flow effect for the non-uniform heat flux distributions boundary. Also, for the case of $\alpha=260^{\circ}$, the average internal heat transfer coefficient increases up to $21 \%$ and $12 \%$ respectively, where the buoyancy effect is present compared to when it is neglected, when the inlet fluid temperature is increased from $293 \mathrm{~K}$ to $340 \mathrm{~K}$, at the same ambient temperature. This indicates the influence of pre-heating the inlet heat transfer fluid on the internal heat transfer coefficient of the absorber tube. 


\subsection{Nusselt numbers for absorber tubes with different diameters and wall thicknesses for non-uniform heat flux distributions}

Fig. 23 shows the variation of the average Nusselt number trends for absorber tubes with different inner diameters and wall thicknesses for $\alpha=140^{\circ}, 180^{\circ}, 220^{\circ}$ and $260^{\circ}$ with an inlet Reynolds number of 800 . The three inner diameters of $62.7 \mathrm{~mm}, 52.5 \mathrm{~mm}$, and $40.9 \mathrm{~mm}$, result in length-to-diameter ratios of 160,191 and 245 respectively. It is found that the average Nusselt number of the tubes increases with an increase in the tube inner diameter and wall thickness for the conditions considered in this paper. These variations could be due to several factors, such as the length-to-diameter ratio, the internal fluid volume available for secondary flow development, and the tube-wall conduction around the circumference which can alter the conjugate heat transfer arrangement. It could be noted that the average Nusselt numbers are well above a value of 10 . Based on this and the analysis comparison conducted in Section 2, the parabolic trough collector adaption will have favorable thermal efficiencies compared to the flat-plate collector type considered here.

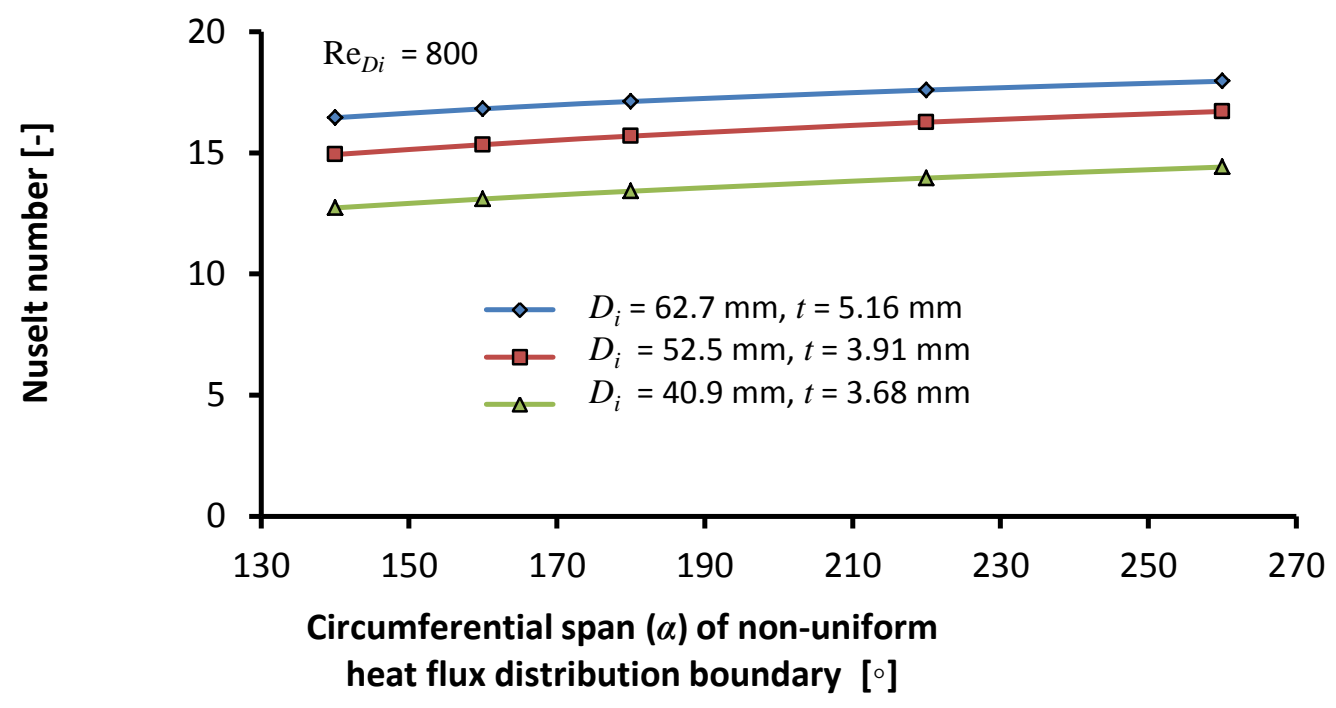

Fig. 23 Average Nusselt number of absorber tubes with different inner diameters and wall thicknesses. 


\subsection{Friction factors for non-uniform heat flux boundaries}

The impact of buoyancy-driven secondary flow and the non-uniform heat flux intensity on the friction factors characteristics of the absorber tube model are shown in Fig. 24 for $\alpha=260^{\circ}$ with base-level heat flux intensities of $21.3 \mathrm{~kW} / \mathrm{m}^{2}$ and $7.1 \mathrm{~kW} / \mathrm{m}^{2}$. The pressure drops for the absorber tube were obtained from the numerical results and subsequently the friction factors were determined from Eq. (26). As expected, the friction factors decrease with an increase in Reynolds number due to the increase in the velocity of the fluid. It is found that where buoyancy effect is present (indicated with the broken lines), the friction factor values for the two heat flux intensities are up to $77 \%$ and $46 \%$ respectively higher than when it is neglected, for the inlet Reynolds number range of 130 to 2200 .

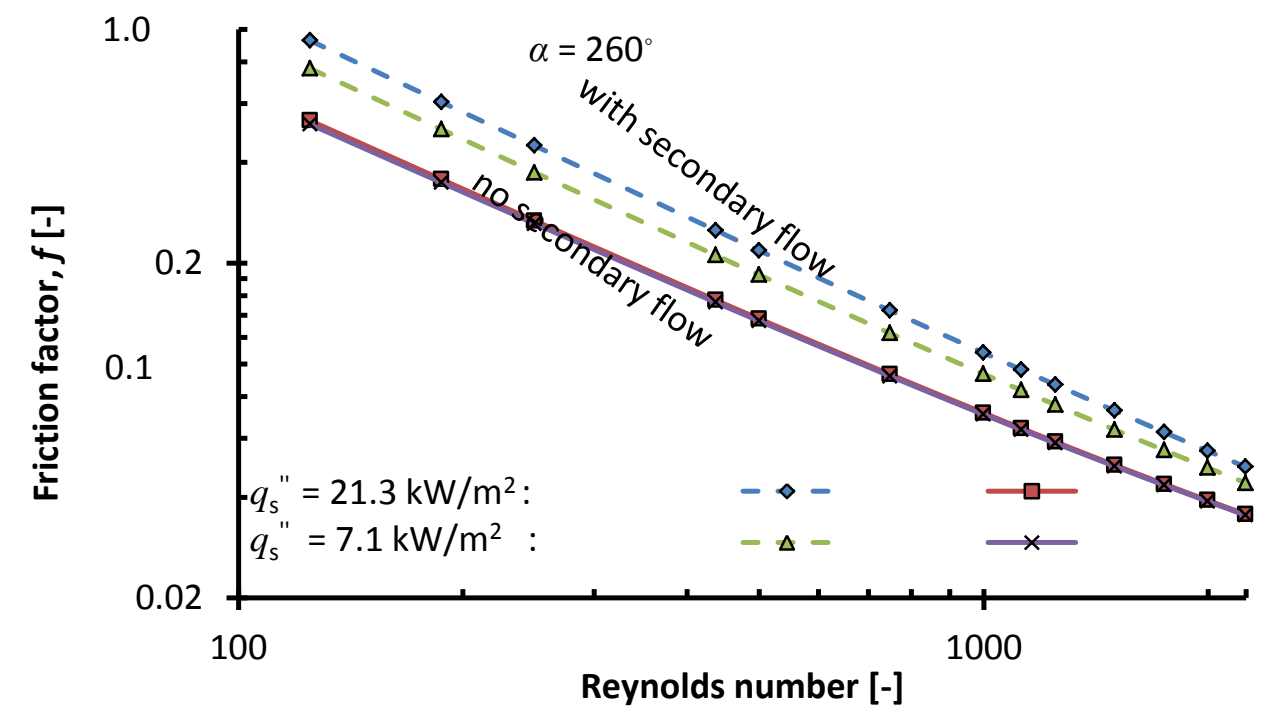

Fig. 24 Variation of the friction factors with Reynolds numbers for a sinusoidal non-uniform heat flux distributions base-level intensities of $21.3 \mathrm{~kW} / \mathrm{m}^{2}$ and $7.1 \mathrm{~kW} / \mathrm{m}^{2}$. 


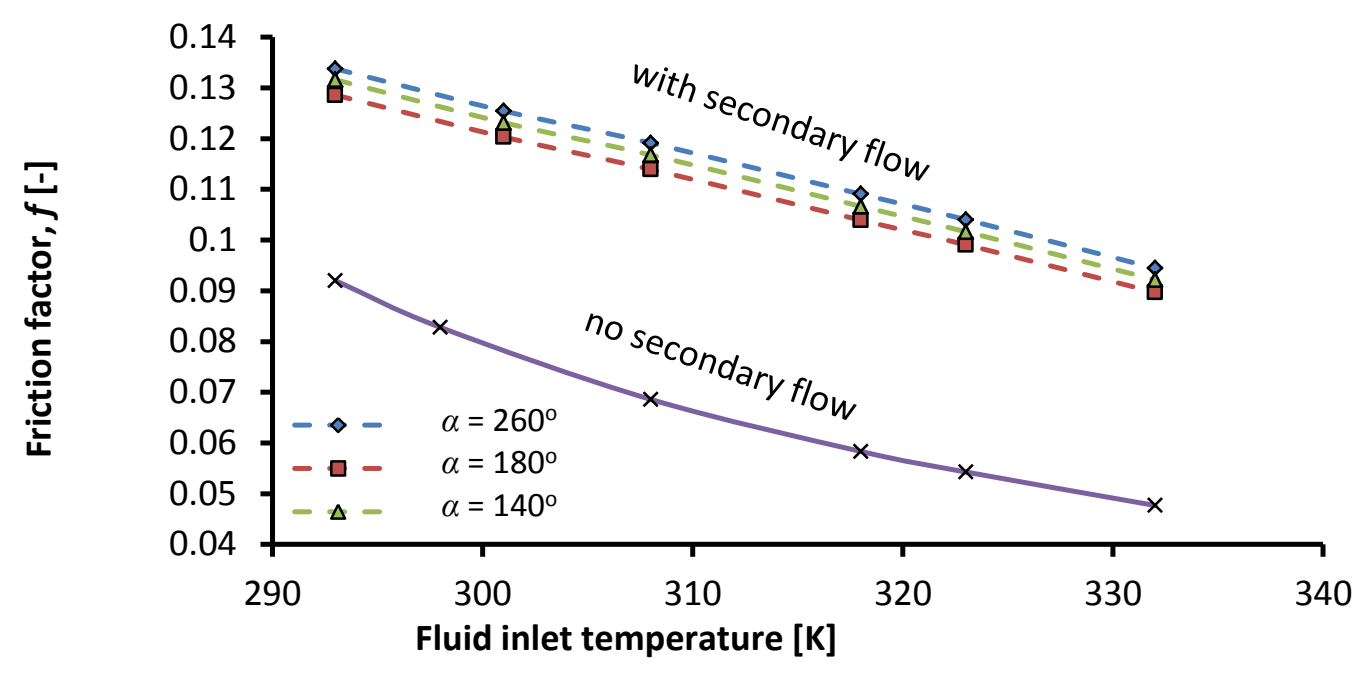

Fig. 25 Variation of the friction factors for an absorber tube at different heat transfer fluid inlet temperature.

Fig.25 indicates the variations of friction factor values in terms of the inlet fluid temperature for $\alpha=140^{\circ}, 180^{\circ}$ and $260^{\circ}$. For the circumferential heat flux spans considered, the friction factor values are up to $88 \%, 93 \%$ and $98 \%$ respectively higher when buoyancy effects are present compared to when they are neglected. Fig. 25 also indicates that the friction factor decreases with an increase in the inlet temperature of the heat transfer fluid.

\section{Conclusion}

In this paper it is shown that an adapted parabolic trough solar collector system operated in the laminar flow regime could be an alternative to flat plate collectors for heating water in applications operated at low mass flow rates such as thermosyphon drive water loops. The improved thermal efficiency associated with higher internal heat transfer coefficient due to buoyancy-induced secondary flow increases the applicability of this solar collector type. Internal convective heat transfer coefficients and friction factors associated with non-uniform heat flux distributions on the external surface of the collector's tubes were determined numerically. A three dimensional steady-state laminar flow model was used for inlet Reynolds numbers ranging from 130 to 2200, tube diameters of $62.7 \mathrm{~mm}, 52.5 \mathrm{~mm}$, and 
$40.9 \mathrm{~mm}$, and different inlet fluid temperatures. It is found that with buoyancy-driven secondary flow present, the internal heat transfer coefficients of the absorber tube increases with the heat flux intensity and spans of the non-uniform heat flux distributions boundary. Also, with the secondary flow effect present, the average internal heat transfer coefficient is up to three times higher than the case of pure forced-convection (no secondary flow effect), indicating higher internal heat transfer enhancement and thus, improved thermal performance. It is also found that with the buoyancy effect present, the friction factor value is approximately twice higher than where it was neglected and that it increases with the heat flux intensity. However, at the same ambient temperature condition, the friction factor value decreases with an increase in the absorber tube inlet fluid temperature, while the internal heat transfer coefficient increased with an increase in the absorber tube inlet fluid temperature.

\section{Further work}

The impact of a glass cover around the absorber tube could be investigated to determine what impact the glass reflection, refraction and absorption might have on the circumferential heat flux distribution.

\section{Acknowledgements}

The funding obtained from the NRF/DST, TESP, Stellenbosch University, University of Pretoria, SANERI/SANEDI, CSIR, EEDSM Hub and NAC is acknowledged and duly appreciated.

\section{References}

[1] S.A. Kalogirou, Solar Thermal Collectors and Applications, Progress in Energy and Combustion Science, 30 (2004) 231-295. 
[2] V.K. Jabasingh and G.M. Joselin Herbert, A Review of Solar Parabolic Trough Collector, Renewable and Sustainable Energy Reviews, 54 (2016) 1085 - 1091.

[3] S.A. Kalogirou, Solar Energy Engineering: Processes and Systems, Academic Press Elsevier Inc, First Edition, 2009.

[4] J.A. Duffie and W. A. Beckman, Solar Engineering of Thermal Processes. Second Edition, A Wiley-Interscience Publication, John Wiley \& Sons, Inc. New York, 1980.

[5] G.N. Tiwari, Solar Energy Fundamental, Design, Modelling and Applications. Narosa Publishing House, 22 Daryaganj, Delhi, India, 2006.

[6] Y. He, J. Xiao, Z. Cheng and Y. Tao, A MCRT and FVM coupled simulation method for energy conversion process in parabolic trough solar collector, Renewable Energy 36 (2011) 976 $-985$.

[7] K. Gasljevic, G. Aguilar, and E.F. Matthys , Buoyancy Effects on Heat Transfer and Temperature Profiles in Horizontal Pipe Flow of Drag-Reducing Fluids International Journal of Heat and Mass Transfer, 43 (2002) 4267- 4274.

[8] S.V. Patankar, Numerical Heat Transfer and Fluid Flow. Hemisphere Publishing Corporation, United States of America, 1980.

[9] O. Zeitoun, Heat Transfer for Laminar Flow in Partially Heated Tubes, Alexandria Engineering Journal, Alexandria University, Egypt, 41 (2) (2002) 205-212.

[10] T. Boufendi and M. Afrid, The Physical Aspect of Three-Dimensional Mixed Convection in a Uniformly Heated Horizontal Pipe, Sciences \& Technologies, 22 (2004) 39-52.

[11] S. Touahri and T. Boufendi, Numerical Study of the Conjugate Heat Transfer in a Horizontal Pipe Heated by Joulean Effect, Thermal Science, 16 (1) (2012) 53 - 67.

[12] S. Piva, G.S. Barozzi, and M. W. Collins, Combined Convection and Wall Conduction Effects in Laminar Pipe Flow: Numerical Predictions and Experimental Validation under Uniform Wall Heating, Heat and Mass Transfer, 30 (1995) 401-409.

[13] A.J. Ghajar and L.-M. Tam, Flow Regime Map for a Horizontal Pipe with Uniform Wall Heat Flux and Three Inlet Configurations, Experimental Thermal and Fluid Science 10 (1995) 287297. 
[14] H.A. Mohammed and Y. K. Salman , Experimental Investigation of Mixed Convection Heat Transfer for Thermally Developing Flow in a Horizontal Circular Cylinder, Applied Thermal Engineering, 27 (2007) 1522-1533.

[15] J. P. Coutier and R. Greif, An Investigation of Laminar Mixed Convection inside a Horizontal Tube with Isothermal Wall Conditions, Int. J. Heat Mass Transfer, 28 (7) (1985) 1293-1305.

[16] A. E. Bergles and R. R. Simonds, Combined Forced and Free Convection for Laminar Flow in Horizontal Tubes with Uniform Heat Flux, Int. J. Heat Mass Transfer, 14 (1971) 1989-2000.

[17] R. Forristall, Heat Transfer Analysis and Modeling of a Parabolic Trough Solar Receiver Implemented in Engineering Equation Solver National Renewable Energy Laboratory 1617 Cole Boulevard Golden, Colorado (2003) 80401-3393.

[18] K.S. Manikandan , R. Kumaresan, R. Velraj, and S. Iniyan, Parametric Study of Solar Parabolic Trough Collector System. Asian Journal of Applied Sciences, 5 (2012) 384-393.

[19] Y. A. Cengel, Heat and Mass Transfer: A Practical Approach, 3rd ed. Published by McGraw-Hill Companies, Inc. 1221 Avenue of the Americas, New York, NY 10020, 2007.

[20] A.A. Badran, M. F. Mustafa, W. K. Dawood, Z. K. Ghazzawi, On the Measurement of Bond Conductance in Solar Collector Absorber Plate, Energy Conversion and Management 49(11) (2008) 3305-3310.

[21] J. Hameury, B. Hay and J-R. Filtz, Measurement of Total Hemispherical Emissivity Using a Calorimetric Technique, Laboratoire National de Métrologie d'Essais (LNE), 29 Avenue Roger Hennequin, 78197 TRAPPES Cedex, France,(2005) 1-14.

[22] L. Theodore, Heat Transfer Applications for the Practicing Engineer, John Wiley \& Sons Inc. Hoboken New Jersey, (2011) $187-188$.

[23] T. A. Moss, and D. A. Brosseau, Final Test Results for the Schott HCE on a LS-2 Collector, Solar Technologies, Sandia National Laboratories Albuquerque, New Mexico 87185 and Livermore, California 94550, NM 87185-1127, 2005.

[24] C.E. Kennedy, Review of Mid- to High-Temperature Solar Selective Absorber Materials NREL/TP-520-31267, National Renewable Energy Laboratory, 1617 Cole Boulevard Golden, Colorado 80401-3393, 2002. 
[25] M. Wirz, M. Roesle and A. Steinfeld , Three-Dimensional Optical and Thermal Numerical Model of Solar Tubular Receivers in Parabolic Trough Concentrators, Journal of Solar Energy Engineering, (2012) 134.

[26] R. K. Rajput, Heat and Mass Transfer in SI Units. Second Edition. Published by S. Chand and Company Ltd, Ram Nagar, New Delhi, 110 055, 2005.

[27] ANSYS Fluent version 14.0, Users' Guide ANSYS, Release 14.0 Incorporated, Southpointe 75 Technology Drive Canonsburg, PA 15317, 2011.

[28] P. M. Khameneh, I. Mirzaie, N. Pourmahmoud, M. R. Eosboee, S. Majidyfar, and M. Mansoor, A Numerical Comparison of Single-Phase Forced Convective Heat Transfer between Round Tube and Straight Microchannel Heat Exchangers, International Journal of Engineering Science and Technology, 2(11) (2010) $6452-6463$.

[29] J. H. Ferziger and M. Perifi, Computational Methods for Fluid Dynamics, 3 Rev. ed.-Berlin; Heidelberg; Hong Kong; London; Milan; Paris; Tokyo: Springer, 2002.

[30] H. K. Versteeg and W. Malalasekera, An Introduction to Computational Fluid Dynamics: The Finite Volume Method. Longman Scientific and Technical, Longman House, Burnt Mill, Harlow Essex CM20 2JE, England, 1995.

[31] F. Burkholder and C. Kutscher, Heat Loss Testing of Schott's 2008 PTR70 Parabolic Trough Receiver, National Renewable Energy Laboratory, Technical Report NREL/TP-550-45633, 2009.

[32] Properties of Syltherm® 800 Heat Transfer Liquid, Midland, MI: Dow Corning Corporation, 1985.

[33] V. E. Dudley, G. J. Kolb, M. Sloan, and D. Kearney, Sand94-1884, Test Results: SEGS LS-2 Solar Collector, Albuquerque, NM, Sandia National Laboratories, 1994.

[34] Z.D. Cheng, Y.L. He, F.Q. Cui, R.J. Xu, Y.B. Tao, Numerical Simulation of a Parabolic Trough Solar Collector with Non-Uniform Solar Flux Conditions by Coupling FVM and MCRT Method, Solar Energy 86 (2012) 1770-1784. 
[35] D. Wen and Y. Ding, Experimental Investigation into Convective Heat Transfer of Nanofluids at the Entrance Region under Laminar Flow Conditions. International Journal of Heat and Mass Transfer, 47 (2004) 5181- 5188.

[36] M. Hallquist, Heat Transfer and Pressure Drop Characteristics of Smooth Tubes at a Constant Heat Flux in the Transitional Flow Regime, M. Eng. Thesis, Department of Mechanical and Aeronautical Engineering, University of Pretoria, South Africa, 2011.

[37] K. Sadik, R. K. Shah, and W. Aung, Handbook of Single-Phase Convective Heat Transfer, A Wiley-Inter-Science Publication John Wiley \& Sons New York, 1987.

[38] A.V.N. Kapatkar, B. A. S. Padalkar and C. S. Kasbe, Experimental Investigation on Heat Transfer Enhancement in Laminar Flow in Circular Tube Equipped with Different Inserts, AMAE Int. J. on Manufacturing and Material Science, 1(1) (2011)1 - 6.

[39] Y. Mori, K. Futagami, S. Tokuda and M. Nakamura, Forced Convective Heat Transfer in Uniformly Heated Horizontal Tubes 1st Report-Experimental Study on the Effect of Buoyancy, International Journal of Heat and Mass Transfer, 9(5) (1966) 453-463. 